\title{
On the Estimation of $\mathrm{CO}_{2}$ Capillary Entry Pressure: Implications on Geological $\mathrm{CO}_{2}$ Storage
}

\author{
Yingfang Zhou a , Dimitrios G. Hatzignatiou ${ }^{b}$, and Johan O. Helland ${ }^{\mathrm{c}}$ \\ a University of Aberdeen (UoA) \\ b University of Houston (UH) \\ c International Research Institute of Stavanger (IRIS)
}

\section{Abstract}

The $\mathrm{CO}_{2}$ entry pressure for a specific pore space decreases with increasing storage site depth because the interfacial tension is reduced and the system becomes less water-wet with increasing depth. This is based on the assumption that the pore throat size and shape remain the same, i.e., they are not stressdependent. The dependency of capillary entry pressure with depth in geological $\mathrm{CO}_{2}$ storage has been reported by only few quantitative investigations, which, however, did not account for the interfacial tension and wettability effects of the brine/ $/ \mathrm{CO}_{2} /$ solid system.

In this work, a workflow and methodology are proposed to quantify the dependency of capillary entry pressure with depth in subsurface geological $\mathrm{CO}_{2}$ storage. The cap-rock pore spaces are treated as straight capillary tubes whose cross-sections are obtained directly from 2D SEM rock images, and the $\mathrm{CO}_{2}$ capillary entry pressure invading these pore spaces is simulated, under arbitrary wetting conditions, with the use of an in-house novel semi-analytical model. In this model, the brine/ $\mathrm{CO}_{2}$ interfacial tension is obtained as a function of the two phases $\left(\mathrm{CO}_{2}\right.$ and brine) density difference, and the contact angle is evaluated based on the Frumkin-Derjaguin equation, and the disjoining pressures isotherm curves is computed from DLVO theory under various $\mathrm{CO}_{2}$ storage pressure, temperature and brine ionic strength conditions. The dependencies of brine/ $\mathrm{CO}_{2}$ interfacial tension, contact angle and capillary entry pressure on $\mathrm{CO}_{2}$ storage depth and brine ionic strength are also investigated.

This newly developed model can be used to compute $\mathrm{CO}_{2}$ entry pressure and associated fluid configurations in realistic cap-rock pore spaces which can be extracted from 2D rock images from core samples located at various storage depths and under the examined storage site's pressure, temperature and brine ionic strength conditions. The proposed workflow for capillary entry pressure estimation and its relationship with depth can enhance our understanding and improve the design and safe storage of $\mathrm{CO}_{2}$ in geological formations.

Key words: Capillary Entry Pressure, Wettability, Interfacial Tension, Contact Angle, DLVO Theory, $\mathrm{CO}_{2}$ Geological Storage

\section{Introduction}

A critical requirement for geological $\mathrm{CO}_{2}$ storage is that $\mathrm{CO}_{2}$ remains stored safely and permanently in the selected subsurface formations. $\mathrm{CO}_{2}$ leakage may potentially occur due to capillary breakthrough of the bulk $\mathrm{CO}_{2}$ phase into the seal (cap rock) through the following mechanisms: (a) exceeding the entry pressure, (b) $\mathrm{CO}_{2}$ diffusion in the brine that is saturating the seal layer, or (c) migration through fractures/faults existing in the cap rock (see for example Chiquet et al., 2005). This work focuses on the first mechanism, the capillary entry pressure, $P_{C E}$, when the $\mathrm{CO}_{2}$ phase pressure $\left(P_{\mathrm{CO}_{2}}\right)$ is high enough to displace water (brine) from the cap rock formation. This threshold capillary pressure $\left(P_{C E}\right)$ for the $\mathrm{CO}_{2}$ phase is given as (see for example Thomas et al., 1968):

$$
P_{c E}=P_{C O_{2}}-P_{w}=\frac{2 \sigma \cos \theta}{r}
$$

where $P_{w}$ is the brine pressure, $r$ is the radius of the pore throats in the cap rock, $\sigma$ is the brine/ $\mathrm{CO}_{2}$ interfacial tension and $\theta$ is the contact angle of the rock(mineral)/brine $/ \mathrm{CO}_{2}$ system measured through the water phase. Eq. 1 gives the capillary entry pressure for $\mathrm{CO}_{2}$ invading brine-filled circular pore spaces with a spherical surface. However, in reality most of the pore geometries are far more complicated than a circular shape. Previous studies, both theoretical (Ma et al., 1996; Lago and Araujo, 2001; Frette and Helland, 2010) and experimental (Plug and Bruining, 2007; Farokhpoor et al., 2013), have shown that the capillary entry pressure depends on the interfacial tension, wetting conditions, pore size, and pore geometry. For a specific pore geometry, the $\mathrm{CO}_{2}$ entry pressure, $P_{c E}$, decreases with 
increasing storage depth (see for example, Tokunaga et al., 2013). This is because (a) the brine/ $\mathrm{CO}_{2}$ interfacial tension decreases with the burial depth as $\mathrm{CO}_{2}$ phase pressure and temperature increase (Hebach et al., 2002; Chalbaud et al., 2009; Bachu and Bennion, 2009; Iglauer et al., 2012); and (b) the system wettability becomes less water-wet with burial depth, which can lead to even lower magnitudes of entry pressure (Chiquet et al., 2005; Yang et al., 2008; Jung and Wan, 2012; Kaveh et al., 2012; Kim et al., 2012; Ameri et al., 2013; Farokhpoor et al., 2013). Finally, with regards to the $\mathrm{CO}_{2}$ trapping capacity, the capillary $\mathrm{CO}_{2}$ trapping increased with pressure (Tokunaga et al, 2013), and the trapped $\mathrm{scCO}_{2}$ was significantly larger than for those for air, and increased with pressure (depth), initial $\mathrm{scCO}_{2}$ saturation, and time in limestone/dolomite sands (Wang and Tokunaga, 2015).

Recently, molecular dynamic modeling was used to estimate contact angles at various temperatures and pressures (Iglauer et al., 2012); this provided a means of linking the intermolecular forces to dropletscale contact angle. However, molecular dynamic modeling is time consuming and the simulated results are strongly affected by the applied boundary conditions and domain size. The absence of relative simple numerical modeling capabilities of interfacial tension and wettability in brine/ $\mathrm{CO}_{2}$ systems makes it difficult to quantify $P_{C E}$ as a function of storage formation depth, especially for realistic pore geometries. A semi-analytical model developed by Frette and Helland (2010) was used to compute capillary entry pressure and associated fluid configurations in straight capillary tubes having realistic irregular crosssections assuming the interfacial tension and contact angle to be known. This model was improved by Zhou et al. $(2013,2014)$ and used to quantify $\mathrm{CO}_{2}$ entry pressure at various wetting conditions. In this enhanced model, the cap-rock pore spaces are treated as straight capillary tubes with realistic crosssections with the brine/ $\mathrm{CO}_{2}$ interfacial tension modelled as a function of the two phases density difference (Hebach et al., 2002), the contact angle evaluated based on the Frumkin-Derjaguin equation (Hirasaki, 1991), and the film thickness related to disjoining pressure based on the Derjaguin-Landau-Verwey-Overbeek (DLVO) theory (Israelachvili, 1991; Hirasaki, 1991; Tokunaga, 2012) using the depth-dependent brine and $\mathrm{CO}_{2}$ properties (phase densities and Hamaker constants). The Zhou et al. $(2013,2014)$ model is used in this work to compute the $\mathrm{CO}_{2}$ entry pressure as a function of hydraulic radius at various storage depths. The dependency of interfacial tension, contact angle and capillary entry pressure on $\mathrm{CO}_{2}$ storage depth and brine ionic strength is also investigated.

In this work, the semi-analytical model and related correlations and theories are presented before the application of the proposed workflow and methodology in a real $\mathrm{CO}_{2}$ storage site case, thus highlighting the importance of estimating the capillary entry pressure and its implications on the geological storage of $\mathrm{CO}_{2}$ in the given formation.

\section{Semi-Analytical Model for Computing Entry Pressure}

As stated above, in this work, $\mathrm{CO}_{2}$ capillary entry pressure and associated fluid configurations are computed iteratively by a semi-analytical model (Frette and Helland, 2010; Helland and Frette, 2010; Zhou et al., 2013, 2014) which is based on generalizing the Mayer and Stowe-Princen (MS-P) method (Ma et al., 1996; Lago and Araujo, 2001) to allow for arbitrary pore shapes from images as tube crosssections. The MS-P method balances the required work with the corresponding change in interfacial free energy for a virtual displacement of the invading main terminal meniscus (MTM) in the direction along the tube length. For a displacement of an MTM separating $\mathrm{CO}_{2}(\mathrm{c})$ and water (w) in a capillary tube, this balance may be written as

$$
\frac{1}{r}=\frac{d A_{c s} \cos \theta+d A_{c w}}{d V_{c}}
$$

where $d A_{c s}$ and $d A_{c w}$ are the changes in $\mathrm{CO}_{2}$-solid and $\mathrm{CO}_{2}$-water interfacial areas, respectively, $d V_{c}$ is the change in $\mathrm{CO}_{2}$ volume, and $\theta$ is the contact angle. The radius of curvature, $r$, of an arc meniscus (AM) located in the pore cross-section sufficiently far away from the MTM is given by the Laplace formula in two dimensions,

$$
r=\frac{\sigma}{P_{c}}
$$

where $\sigma$ is the interfacial tension. The capillary entry pressure for a displacement of the MTM is related to the AM radius by Eq. 3 . The MS-P method has been used to derive entry pressures in idealized pore geometries (Ma et al., 1996; Øren et al., 1998; Lago and Araujo, 2001), and more recently, in arbitrary, yet relatively convex, polygonal pore shapes by making use of the relation between the entry fluid configuration and the medial axis of the pore space (Lindquist, 2006).

\subsection{Capillary entry pressure radii and associated fluid configurations}


The semi-analytical model (Frette and Helland, 2010) requires as input a 2D binary solid-void image. Smooth pore/solid boundaries $\Gamma$ are calculated by a Euclidean path method (Braquelaire and Vialard, 1999) based on the discrete boundaries that are identified in the binary image. Orientation angles $\alpha$ are then computed for all boundary points $b \in \Gamma$. The angle $\alpha$ is defined between the boundary tangent at $\mathrm{b}$ and a line parallel with the abscissa (please refer to Figure 1a). The next step in the procedure is determining the entry pressure and associated cross-sectional fluid configurations in the binary image during capillary-controlled invasion for a non-wetting phase (e.g., $\mathrm{CO}_{2}$ ) displace wetting phase (e.g., brine water) under arbitrary wetting conditions $(\theta)$.

The most favorable entry curvature for a given capillary pressure radius, $r$, in a realistic pore geometry is determined by the following three steps. First, run an arc meniscus determining procedure to find out all the geometrically allowed interfaces. Second, run the pore boundary tracking algorithm to find out all possible invasion candidates; and third compute the capillary entry curvatures for all the possible invasion candidates and determine the most favorable invasion which corresponds to the smallest entry curvature among the invasion candidates.

For a given capillary pressure radius, $r$, a circle with radius $r$ is moved along the pore boundary in opposite directions such that the front arcs form the given contact angle $\theta$ in the boundary points. The loci of the circle centers constitute two closed curves which are given by:

$$
\begin{aligned}
& v_{i}^{c c}=\left(x_{i}-r \sin \left(a_{i}+\theta\right), y_{i}+r \cos \left(a_{i}+\theta\right)\right), \\
& v_{i}^{c}=\left(x_{i}-r \sin \left(a_{i}-\theta\right), y_{i}+r \cos \left(a_{i}-\theta\right)\right),
\end{aligned}
$$

where $(x, y)$ are the coordinates of the pore boundary point $b$, and $\theta$ is the contact angle. Geometrically allowed arc menisci occur at locations where the circles moving in opposite directions intersect and the coinciding arcs point toward pore-space constrictions or corners, as shown in Figure 1a. Geometrical regions, with boundaries composed of alternate pore-wall segments and AMs, are determined by a poreboundary tracking procedure. These regions are classified as bulk phase regions (BR) or layer phase regions (LR) based on the orientation of the AMs that belong to the region boundaries.

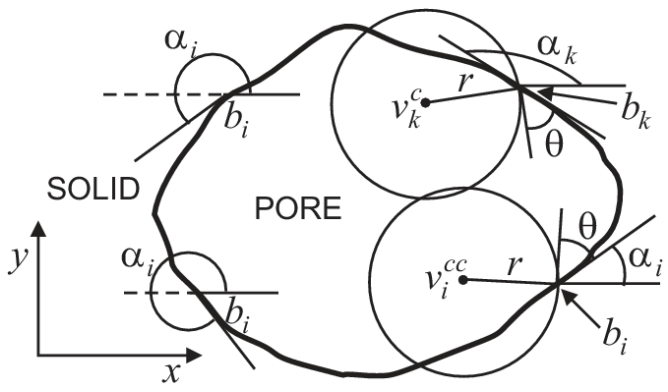

(a)

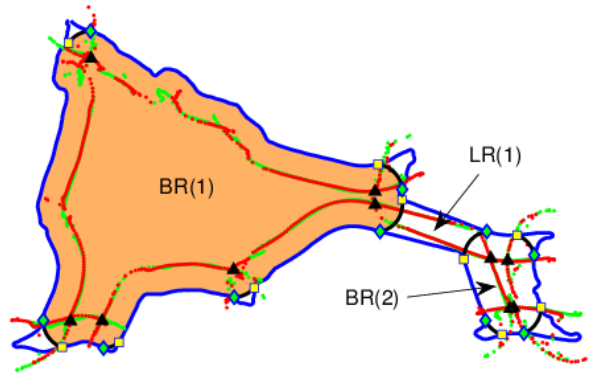

(b)

Figure 1: Numerical examples of the Frette and Helland (2010); Zhou et al. (2013, 2014) semi-analytical model in an extracted pore space from Bentheim sandstone for (a) definition of the orientation angle, $\alpha_{i}$ at point $b_{i}$, and the relation between counter-clockwise and clockwise closed curves, $v^{c c}$ and $v^{c}$, the parameters $r$ and $b$ are illustrated for a nonzero contact angle, $\theta$. (b) The relation between $b \in \Gamma$ (blue solid curve), $v^{c c}$ (red dotted

curve), $v^{c}$ (green dotted curve), circle intersections (black triangles), AMs (black solid curves) and the corresponding contact lines (yellow squares, green diamonds) are shown. Figure $1 \mathrm{~b}$ also shows the favorable configuration (colored region) of the invading fluid $\left(\mathrm{CO}_{2}\right)$ at the given capillary pressure.

The valid fluid configuration change is associated with the most favorable entry pressure among all possible displacement scenarios. Therefore, entry pressures are computed for all valid BR and LR combinations that could be formed by the invading fluid. The general MS-P equation for region combination $i$ is given by

$$
F_{i}(r)=\frac{L_{o s, i} \cos \theta+L_{o w, i}}{A_{o, i}},
$$


where $A_{o, i}$ is the cross-sectional area of the invading fluid, $L_{o s, i}$ and $L_{o w, i}$ are the solid length contacted by the invading fluid and the lengths of the AMs during the displacement, respectively.

142 The most favorable entry curvature among all available displacement scenarios $N_{c}$ is determined by:

$$
F^{*}(r)=\min \left\{F_{i}(r): \frac{1}{r} \geq F_{i}(r), i=1, \ldots, N_{c}\right\} .
$$

144

145

146

147

148

149

A computational example of the most favorable capillary entry curvature, and its associated fluid configurations among all the interfaces combination at a given interface radius, is given in Figure $1 \mathrm{~b}$. Based on the 10 geometrically allowed AMs, the three regions $B R(1), L R(1)$, and $B R(2)$, are identified. The allowed region combinations for possible gas invasion are given by $\{B R 1\},\{B R 2\}$ and $\{B R 1, L R 1$, BR2\}. From Eqs. 5 and 6 it is found that the most favorable entry pressure $F^{*}(r)$ corresponds to the individual region $\{B R 1\}$ and its associated fluid configuration is defined and highlighted with the orange color in Figure $1 \mathrm{~b}$.

The entry curvature and associated fluid configurations for a non-wetting phase displacing the wetting phase in a straight tube with highly irregular cross section under arbitrary wetting conditions are determined through an iterative procedure,

$$
\left|r_{i t e r}-\frac{1}{F^{*}\left(r_{i t e r}\right)}\right|<10^{-6}
$$

where $F^{*}(r)$ is the most favorable capillary curvature among all possible displacement scenarios for the present iteration radius, $r_{i t e r}$. Note that the initial value of $r_{i t e r}$ is considered to be the effective hydraulic radius $r_{1}=A / L \cos \theta$, where $A$ and $L$ are the pore space cross-sectional area and boundary perimeter, respectively.

\subsection{Capillary entry radii correlation}

A segmented Bentheim sandstone SEM image, as shown in Figure 2, is used to calculate the capillary entry radii for highly irregular pore space as described in Section 2.1. This image size is $1134 \times 761$ pixels and its resolution $0.204 \mu \mathrm{m}$. As shown in this figure, the black entries represent pore space and the white background denotes matrix. In this rock image, 293 individual pore spaces could be extracted and the total porosity equals 0.18 . The basic properties, such as pore boundary, pore area, pore boundary length are calculated first for each pore space, and then the capillary entry radii are computed at different wetting conditions, $\theta$, for each of these extracted individual pore geometries using the semi-analytical model described above.

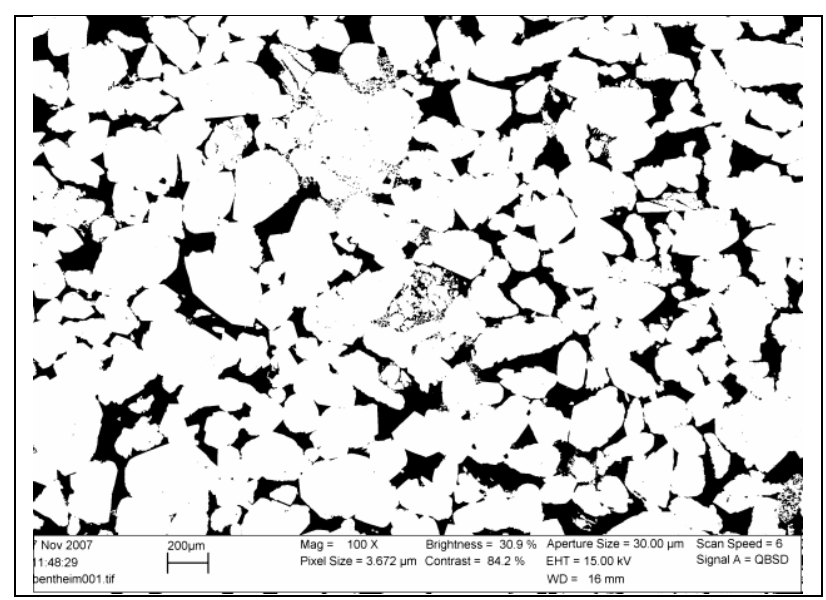

Figure 2: SEM image of Bentheim sandstone which is taken as input to the proposed modeling procedure.

170 The simulated capillary entry radii for three wetting conditions, $\theta=0^{\circ}, 30^{\circ}, 60^{\circ}$, are plotted in Figure $3 a$

171 as a function of the effective hydraulic radius $A / L \cos \theta$. Lindquist (2005) demonstrated that the hydraulic 
radius $A / L$ provides an accurate prediction of capillary entry radii in relative convex pore geometries under strongly water-wet conditions. Since the Bentheim sandstone pore spaces are strongly nonconvex and show a high degree of surface roughness, Frette and Helland (2010) concluded that the hydraulic radius $A / L$ under-estimates the capillary entry radii at strongly water-wet conditions, and proposed an improved formulation to estimate the capillary entry radii of non-wetting phase invading into highly irregular wetting-phase filled pore throats,

$$
r_{E}=\frac{g(\theta) A}{L \cos \theta}
$$

where $g(\theta)$ is a function of contact angle. As shown in Figure 3a, the slope of the potential trend curve decreases as the data set changes from strongly to weakly water-wet conditions, indicating that $g(\theta)$ decreases with pore space wettability. Figures $3 b$ and $3 c$ present capillary entry radii as a function of effective hydraulic radius along with their fitted straight lines for $\theta=0^{\circ}$ and $\theta=70^{\circ}$ respectively, thus demonstrating that $g(\theta)$ decreases dramatically when the wettability varied from strongly to weakly water-wet conditions. It has to be noted that $g(\theta)$ is smaller than 1 at weakly water-wet conditions; this is expected since relatively flat interfaces and larger invading fluid areas will be examined, and thus the effects of pore boundary roughness and pore shape on the capillary entry radius in pore space are 187 attenuated.

188 The capillary entry radii were computed at various wetting conditions (contact angles), and $g(\theta)$ was estimated by fitting the computed capillary entry radii as a function of effective hydraulic radius using a straight line correlation. The computed $g(\theta)$ values are plotted versus $A / L \cos \theta$ in Figure $3 d$ as green circles, and a polynomial correlation is used to correlate these computed $g(\theta)$ data as a function of contact angle:

$$
g(\theta)=1.9098(\cos \theta)^{4}-4.5329(\cos \theta)^{3}+3.8967(\cos \theta)^{2}-1.0857 \cos \theta+1.0344 .
$$

194 Therefore, the capillary entry radii for the invasion of a non-wetting phase into a realistic pore geometry 195 filled with the wetting phase can be evaluated from Eqs. 8 and 9 under arbitrary wetting conditions, and 196 this will be used later to calculate the capillary entry pressure as given in Eq. (23).

197

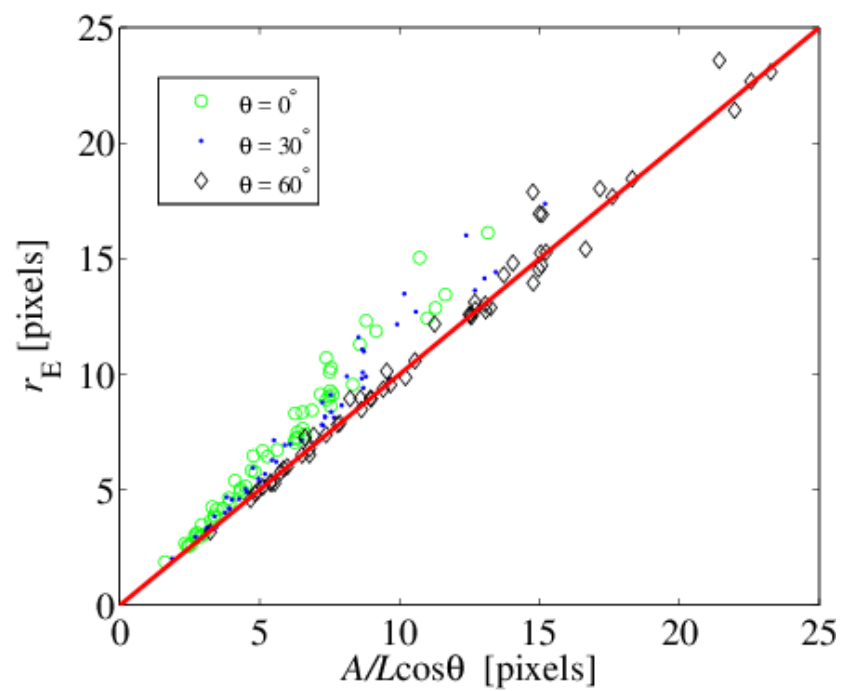

(a)

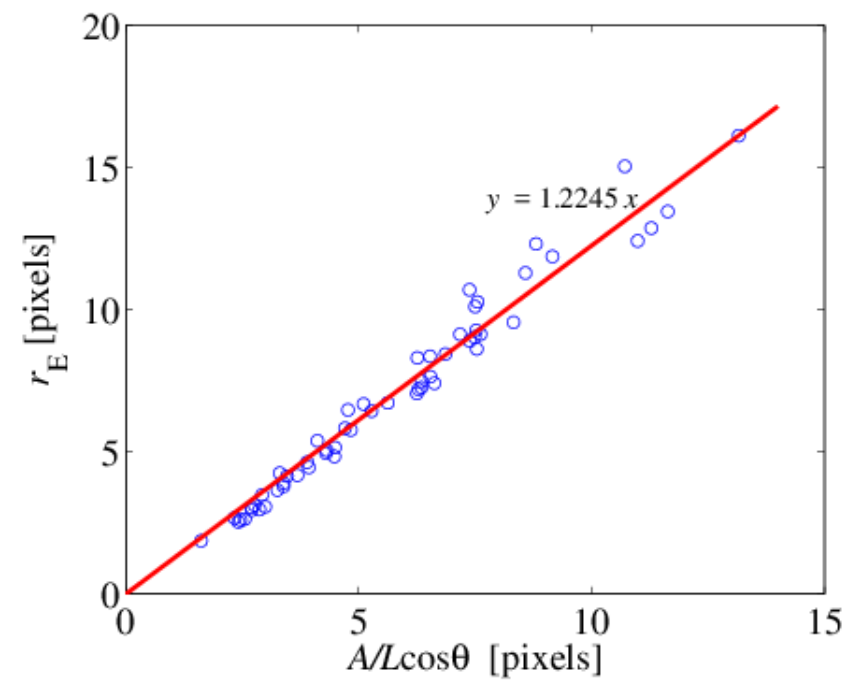

(b) 


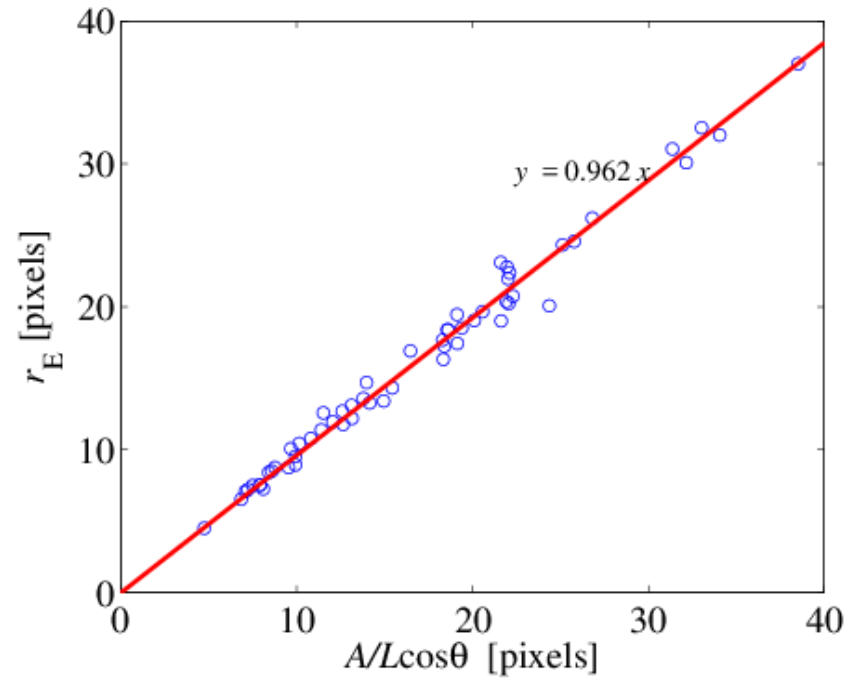

(c)

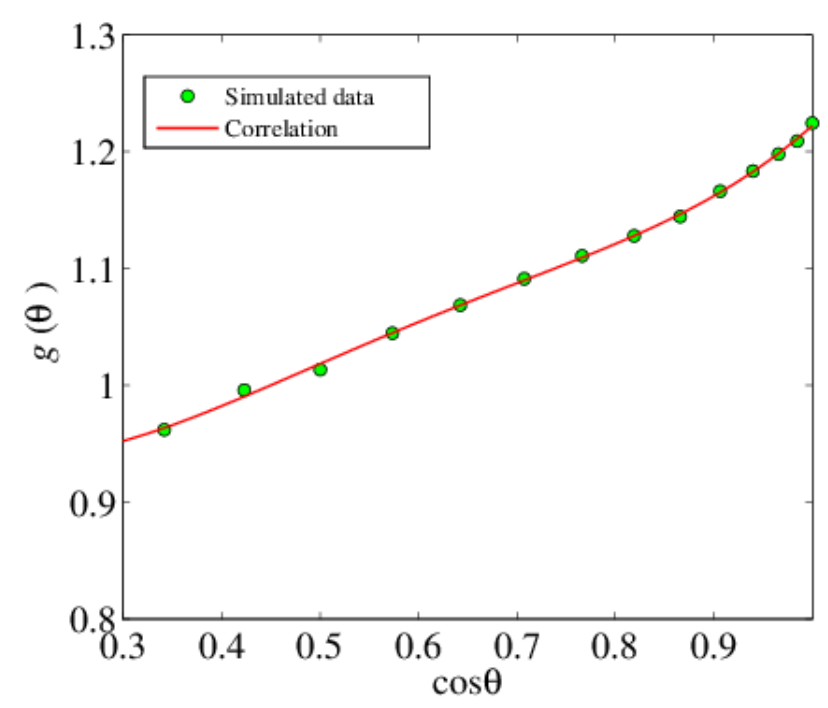

(d)

Figure 3: Computed capillary entry radii and impact of contact angle. (a) Capillary entry radii as a function of effective hydraulic radius under three wetting conditions; (b) capillary entry radii as a function of effective hydraulic radius under strongly water-wet condition, $\theta=0^{\circ}$; and (c) $\theta=70^{\circ}$, (d) $g(\theta)$ as a function of $\cos \theta$. Note that $\theta$ varies from $0^{\circ}$ to $70^{\circ}$ at a $5^{\circ}$ interval; this correlation is used in Eq. (23).

\section{Depth-Dependent Properties}

Significant pressure, $P$, and temperature, $T$, changes may be experienced with increasing depth below the earth's surface, but also during the injection of $\mathrm{CO}_{2}$ in a given storage site, which cause variations in several basic rock/fluid properties, such as interfacial tension and contact angle, that affect capillary equilibrium. The importance of $P$ and $T$ variations is evident when considering the interfacial tension and contact angle depth profiles using typical geothermal gradients ranging from 20 to $30 \mathrm{~K} \mathrm{~km}^{-1}$ (Celia, 2008) and a typical hydrostatic pressure gradient of $10.5 \mathrm{MPa} \mathrm{km}^{-1}$ (Deming, 2001).

For estimating the entry pressure, properties which are highly dependent on depth include the: (a) brine $/ \mathrm{CO}_{2}$ interfacial tension and contact angle, which affect the capillary entry pressure and fluid configuration; (b) density of $\mathrm{CO}_{2}$, which affects capillary pressure and DLVO interactions; (c) dielectric constants of brine water and $\mathrm{CO}_{2}$, which affect electrostatic and van der Waals interactions; and (d) Hamaker constants, which are central to calculating van der Waals interactions. The variation of these parameters as a function of depth and their calculation will be discussed in following subsections.

\subsection{Interfacial tension computation}

The interfacial tension between $\mathrm{CO}_{2}$ and brine has a significant influence on the effectiveness of any $\mathrm{CO}_{2}$ storage operations. However, to the best of our knowledge, there are only two existing models in the literature that can be used to predict the interfacial tension between $\mathrm{CO}_{2}$ and brine (Hebach et al., 2002; and Chalbaud et al., 2009). These two proposed empirical models are both obtained from regression fits of experimental data and predict the interfacial tension at various temperature and pressure conditions from the density difference between the brine water and $\mathrm{CO}_{2}$. In this work, we choose the correlation proposed by Hebach et al. (2002) to compute the interfacial tension $\sigma$; this correlation is given as:

where

$$
\sigma=k_{0}\left[1-\exp \left(k_{1} \sqrt{d}\right)\right]+k_{2} d+k_{3} d^{2}+k_{4} d^{2}+k_{5} \exp \left[k_{6}(d-0.9958)\right]
$$

and

$$
d=\left[\left(\rho_{\text {Brine }}-\rho_{\text {corr }}\right) / 1000\right]^{2}
$$

$$
\rho_{\text {corr }}=\left\{\begin{array}{cl}
\rho_{\mathrm{CO}_{2}}+b_{0}(304-T) P^{b_{1}}, & \text { if } 25 \mathrm{~kg} \cdot \mathrm{m}^{-3}<\rho_{\mathrm{CO}_{2}}<250 \mathrm{~kg} \cdot \mathrm{m}^{-3} \\
\rho_{\mathrm{CO}_{2}}, & \text { for all other cases }
\end{array}\right.
$$

Note that $d$ is a function of temperature and pressure, and it represents the square density difference of the two components (brine water and $\mathrm{CO}_{2}$ ), fluid densities are measured in $\mathrm{kg} / \mathrm{m}^{3}$, and the units of temperature and pressure ( $\mathrm{T}$ and $\mathrm{P}$ ) are in $\mathrm{K}$ and $\mathrm{MPa}$, respectively. The various coefficients of this 
regression function are $b_{0}=0.00022, b_{1}=-1.9085, k_{0}=27.514, k_{1}=-35.25, k_{2}=31.916, k_{3}=-91.016$, $234 k_{4}=103.233, k_{5}=4.513$ and $k_{6}=351.903$. Using this empirical equation to model interfacial tension 235 between brine and $\mathrm{CO}_{2}$ requires the density of brine water and $\mathrm{CO}_{2}$ at given conditions.

Brine water density. The density of water as a function of both temperature and pressure can be expressed as (The Engineering ToolBox, from online source, http://www.engineeringtoolbox.com/fluiddensity-temperature-pressure-d_309.html):

$$
\rho_{w, 1}=\frac{\rho_{w, 0}}{1+\beta\left(T_{1}-T_{0}\right)} \frac{E}{E-\left(P_{1}-P_{0}\right)}
$$

where $\rho_{w, 0}$ is the water density $\left(\mathrm{kg} / \mathrm{m}^{3}\right)$ at pressure of $P_{0}(\mathrm{MPa})$ and temperature of $T_{0}\left({ }^{\circ} \mathrm{C}\right), \beta$ is water volumetric temperature expansion coefficient $\left(1 /{ }^{\circ} \mathrm{C}\right)$ and $E$ is the water bulk modulus of elasticity $(=2150$ MPa). We set $\rho_{w, 0}=999.8 \mathrm{~kg} \cdot \mathrm{m}^{-3}$ at $P_{0}=1.1 \mathrm{MPa}$ and $T_{0}=0^{\circ} \mathrm{C}$ for computing the pure water density. The brine water density is adjusted based on pure water density and the ionic strength. For example, the $\mathrm{NaCl}$ brine density with an ion concentration equal to $c\left(\mathrm{~mol} / \mathrm{m}^{3}\right)$ is approximated by:

$$
\rho_{b}=\left(1-\frac{c \cdot M W_{N a C l}}{\rho_{\mathrm{NaCl}}}\right) \cdot \rho_{w, 1}+\frac{c \cdot M W_{\mathrm{NaCl}}}{\rho_{\mathrm{NaCl}}},
$$

where $M W_{\mathrm{NaCl}}$ is the molecular weight of $\mathrm{NaCl}(=58.44 \mathrm{~g} / \mathrm{mol})$, and $\rho_{\mathrm{NaCl}}$ is the density of solid $\mathrm{NaCl}$ $\left(=2.16 \times 10^{3} \mathrm{~kg} \cdot \mathrm{m}^{-3}\right)$.

$\mathrm{CO}_{2}$ density. The density of pure $\mathrm{CO}_{2}$ was measured by Span and Wagner (1994) under various pressures and temperature; these data are shown in Figure 4 as a function of pressure and temperature. In our work, a linear interpolation method is used to compute the density of $\mathrm{CO}_{2}$ under arbitrary combinations of temperature and pressure conditions that could be encountered at various $\mathrm{CO}_{2}$ storage depths.

\subsubsection{Interfacial tension at $\mathrm{CO}_{2}$ storage depths}

Based on the above procedures, the $\mathrm{CO}_{2}$ density, $\rho_{\mathrm{co}}$, and the brine water / $\mathrm{CO}_{2}$ density difference (for three ionic concentrations) are presented in Figure 5. The lack of close form analytical expressions for the $\mathrm{CO}_{2}$ density, brine refractive index and $\mathrm{CO}_{2}$ dielectric constant versus pressure and temperature requires interpolation in the corresponding data sets (see Figures 4, 7 and 8 , respectively), which yields non-smooth fluid density versus depth curves as the ones depicted in Figure 5 . The surface pressure is set to $0.105 \mathrm{MPa}$ and surface temperature to $20^{\circ} \mathrm{C}$; the pressure gradient equals to $10.5 \mathrm{MPa} / \mathrm{km}$ and the temperature gradient equals to $20.5 \mathrm{~K} / \mathrm{km}$. This figure shows that $\mathrm{CO}_{2}$ density and density differences vary significantly at depth range of $700-1000$ meters; this is because $\mathrm{CO}_{2}$ exists at supercritical state at the given depth range for the corresponding temperature and pressure gradients. The brine density is affected by ionic concentration, as shown in Figure 5, however, the presented three density difference-depth curves $(\mathrm{c}=0.01 \mathrm{M}, 0.1 \mathrm{M}, 1 \mathrm{M})$ do not exhibit a significant variation at same pressure and temperature conditions. Based on the determined density difference, the interfacial tensions for the various depths, and at different ionic concentrations, are computed from the model proposed by Hebach et al. (2002), and the results are presented in Figure 6. This figure shows that the 


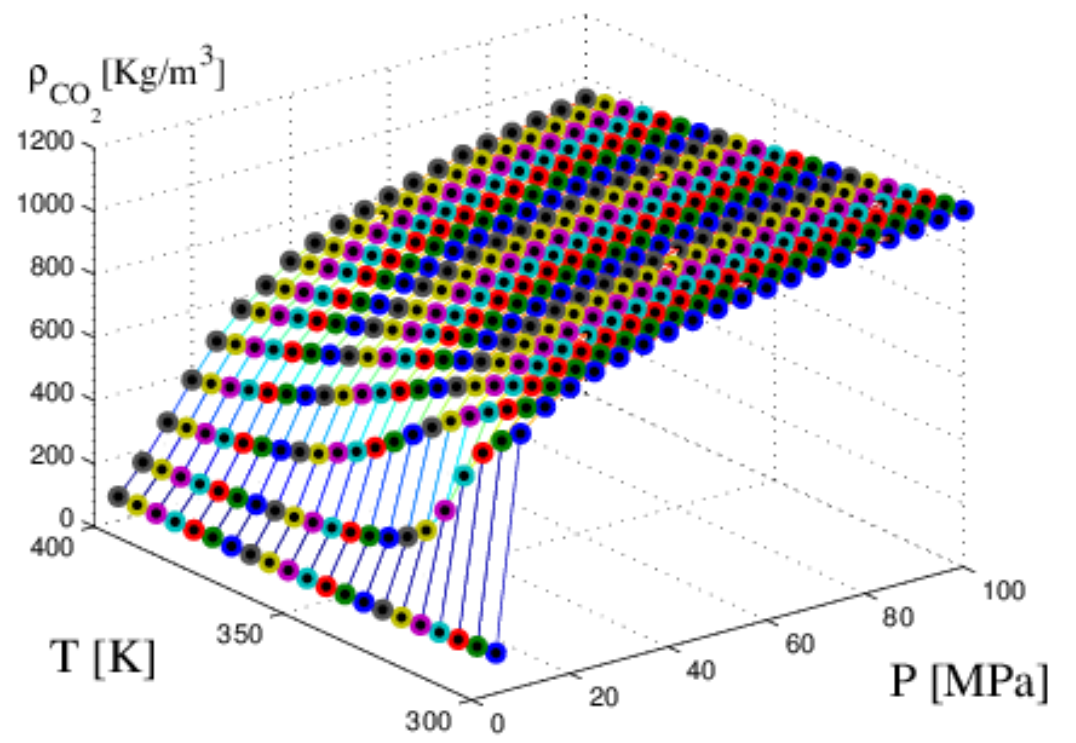

Figure 4: Pure $\mathrm{CO}_{2}$ density at various pressure and temperature conditions (Span and Wagner, 1994).

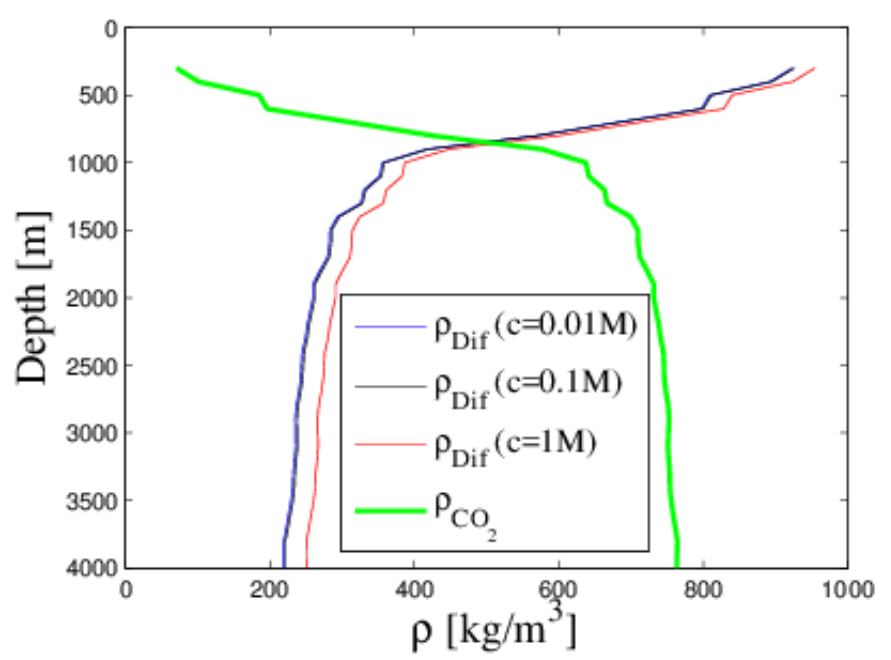

Figure 5: $\mathrm{CO}_{2}$ density, density difference between brine/water $(\mathrm{C}=0.01 \mathrm{M}, 0.1 \mathrm{M}, 1 \mathrm{M})$ and $\mathrm{CO}_{2}$ at various depths Pressure gradient $10.5 \mathrm{MPa} / \mathrm{km}$ and temperature gradient $20.5 \mathrm{~K} / \mathrm{km}$.

\subsection{Wettability (contact angle) modeling}

275 Direct integration of the augmented Young-Laplace equation of capillarity

$$
P_{c}=\frac{\sigma}{r}+\Pi\left(f^{*}\right)
$$

yields the following relationship between the equilibrium contact angle, $\theta$, and the disjoining pressure,

$$
\cos \theta=1+\frac{f^{*} \Pi\left(f^{*}\right)+\int_{f^{*}}^{\infty} \Pi(f) d f}{\sigma}
$$

where $r$ is the interfacial curvature and $f^{*}$ is the equilibrium film thickness of interest. Depending on the magnitude of the right-hand side of Eq. 14, both perfect wetting and non-perfect wetting conditions can be examined. Eq. 14 is known as the Frumkin-Derjaguin equation (Hirasaki, 1991; Chaturvedi et al., 2009) and links the macroscopic contact angle $\theta$ to the interaction forces between a solid surface and a fluid-fluid interface. The concept of disjoining pressure is used to reflect the contribution of the 
interaction forces on the solid wettability. In the next step, the DLVO theory will be introduced to compute the disjoining pressure isotherm curves at various temperature, pressure and ionic strength conditions that might be encountered in $\mathrm{CO}_{2}$ storage sites. This, for example, includes the cap-rock located at different depths that prevents $\mathrm{CO}_{2}$ leakage, as well as impermeable layers or laminations located either in the storage formation or in the overburden strata that prevent or delay the vertical migration of $\mathrm{CO}_{2}$ within the storage formation or through the overburden in case of an unwanted $\mathrm{CO}_{2}$ leakage, respectively.

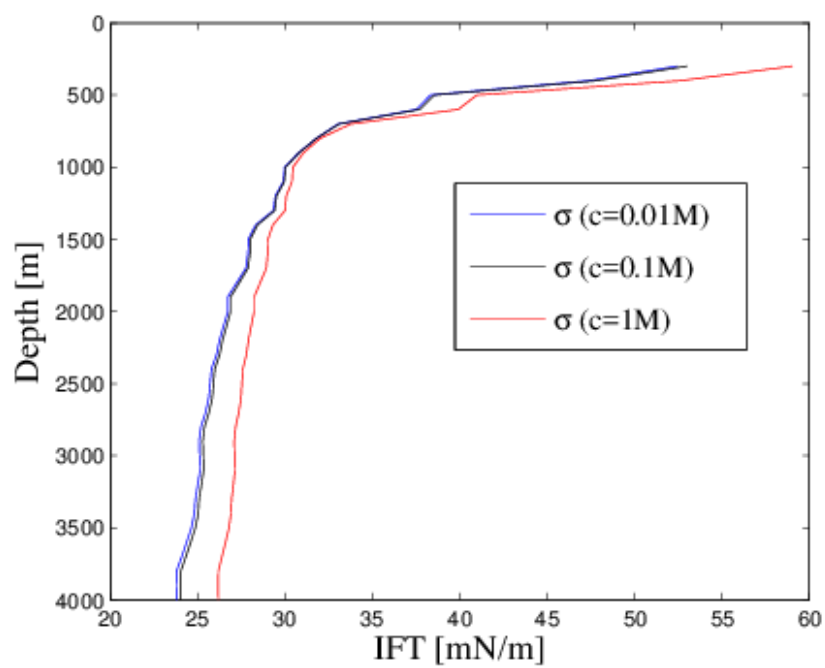

292

Figure 6: Interfacial tension between $\mathrm{CO}_{2}$ and brine/water as a function of depth for various ionic concentrations $(c=0.01 \mathrm{M}, 0.1 \mathrm{M}, 1 \mathrm{M})$; pressure gradient $10.5 \mathrm{MPa} / \mathrm{km}$ and temperature gradient $20.5 \mathrm{~K} / \mathrm{km}$.

\subsubsection{Disjoining pressure}

DLVO theory suggests that the interaction forces between a solid surface and a gas-water interface are either attractive or repulsive. The disjoining forces have three components: (a) van der Waals forces $F_{v d W}$, (b) structural forces $F_{s}$, and (c) electrostatic interactions $F_{e}$ originating from the overlap of ion clouds at each interface. The sum of these forces $\left(F_{v d W}, F_{s}, F_{e}\right)$ results in the disjoining pressure, $\Pi$, between the surfaces. Here, the structural forces are considered to be pressure-temperature independent, while the van der Waals forces and electrostatic interactions will be evaluated under various pressure-temperature conditions characteristic of geological $\mathrm{CO}_{2}$ sequestration. Subsequently, the predicted combined effect of these forces on the disjoining pressure isotherm curves, and consequently on the wettability of cap-rock pore spaces, will be estimated.

Structural forces. Structural forces explain the repulsion when two molecules come near each other. In general, these forces decrease exponentially with increasing film thickness, $h$ :

$$
F_{s}=A_{s} e^{-f / f_{s}},
$$

where $A_{s}$ is a coefficient for the structural force and it depends on the type of solid/fluid system, $f$ is the thickness of the film, and $f_{s}$ is the decay length. In this work, we have used $f_{s}=0.05 \mathrm{~nm}$ as suggested by Hirasaki (1991).

van der Waals forces. van der Waals forces are dependent on the distance between any two surfaces, for thin-film interactions, and are given by (Hirasaki, 1991),

$$
F_{v d W}=\frac{-H_{v d W}}{6 \pi f^{3}},
$$

where $H_{v d W}$ is the Hamaker constant for the interactions in the brine/ $\mathrm{CO}_{2}$ system. The value of the Hamaker constant in Eq. 16 is approximated by the geometric mean of Hamaker constants in the brine/brine and $\mathrm{CO}_{2} / \mathrm{CO}_{2}$ systems:

$$
H_{v d W}=\left(\sqrt{H_{b b}}-\sqrt{H_{c c}}\right)\left(\sqrt{H_{b b}}-\sqrt{H_{s s}}\right) .
$$


The Hamaker constants for the brine/brine, $\mathrm{CO}_{2} / \mathrm{CO}_{2}$ and solid/solid systems, under given temperature and pressure conditions, are computed in terms of the refractive index and the dielectric permittivity of the system (Israelachvili, 1991):

$$
H_{i i}=\frac{3}{4} k_{B} T\left(\frac{\varepsilon_{i}-1}{\varepsilon_{i}+1}\right)^{2}+\frac{3 h v_{e}}{16 \sqrt{2}} \frac{\left(n_{i}^{2}-1\right)^{2}}{\left(n_{i}^{2}+1\right)^{\frac{3}{2}}} .
$$

Here $k_{B}$ denotes the Boltzmann constant, $v_{e}$ is the absorption frequency, $\varepsilon_{i}$ are the dielectric constants and $n_{i}$ the refractive indices for $\mathrm{CO}_{2}$ and brine (subscript $i$ represents either $\mathrm{CO}_{2}$ or brine). The dielectric constants and refractive indices of the brine/water and $\mathrm{CO}_{2}$ are pressure-temperature dependent properties. The computation of these four intermolecular fluid properties have been reported in the literature, and are described briefly below.

The pressure-temperature dependent brine water dielectric constant $\varepsilon_{b}$ is computed from the empirical correlation proposed by Bradley and Pitzer (1979):

$$
\varepsilon_{b}=D_{1000}+C \ln \left(\frac{B+P}{B+1000}\right) .
$$

The definitions of the various variables in Eq. 19 are as follows:

$$
D_{1000}=U_{1} \exp \left(U_{2} T+U_{3} T^{2}\right),
$$

$$
C=U_{4}+U_{5} /\left(U_{6}+T\right) \text {, }
$$

$$
B=U_{7}+U_{8} / T+U_{9} T \text {, }
$$

334 where $U_{1}=3.4279 \times 10^{2}, U_{2}=-5.0866 \times 10^{-3}, U_{3}=9.4690 \times 10^{-7}, U_{4}=-2.0525, \quad U_{5}=3.1159 \times 10^{3}$, $U_{6}=-1.8289 \times 10^{2}, U_{7}=-8.0325 \times 10^{3}, U_{8}=4.2142 \times 10^{6}$, and $U_{9}=2.1417$.

336 One of the other pressure-temperature properties, the brine water refractive index $n_{b}$, is taken from Harvey et al. (1998) at a wavelength equal to $0.58926 \mu \mathrm{m}$ and plotted as a function of pressure and temperature in Figure 7.

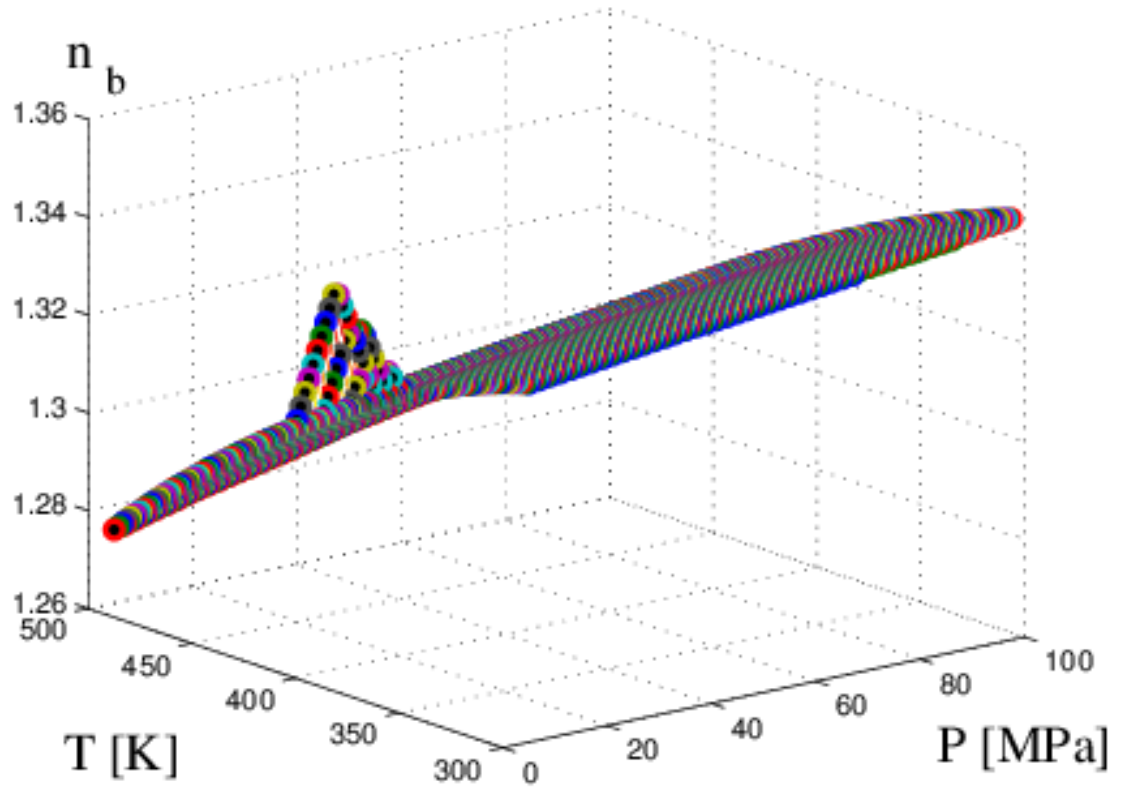

Figure 7: Brine refractive index as a function of temperature and pressure; wavelength equal to $0.58926 \mu \mathrm{m}$. 
The pressure-temperature dependent refractive index for $\mathrm{CO}_{2}, n_{c}$, is computed using the correlation proposed by Sun et al. (2003):

$$
n_{c}=0.2371 \rho_{\mathrm{CO} 2}+0.9983 \text {. }
$$

344 The pressure-temperature dependent dielectric constant for $\mathrm{CO}_{2}, \varepsilon_{c}$, is taken from Michels and Michels 345 (1933), and plotted as a function of pressure and temperature in Figure 8.

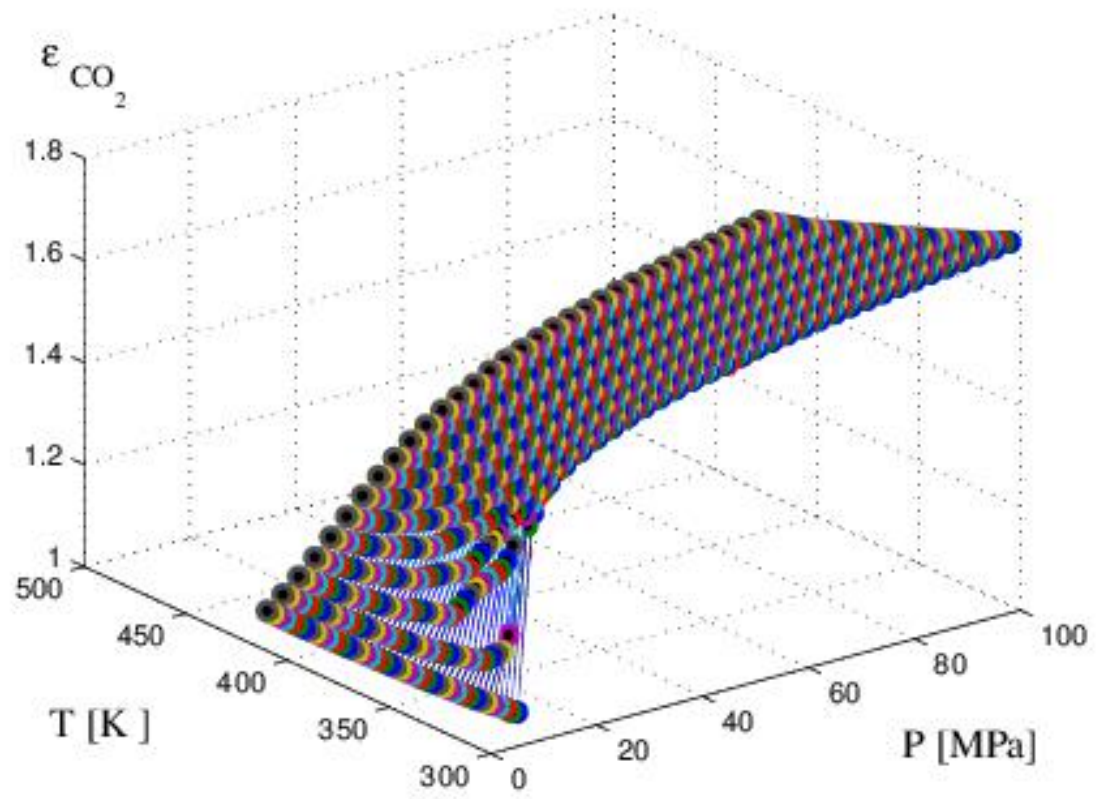

Figure 8: $\mathrm{CO}_{2}$ dielectric constant as a function of temperature and pressure.

Electrostatic forces. The two surfaces of a colloidal thin film may interact because of the presence of an ionic charge on these surfaces. The forces between the two surfaces are usually calculated by modelling these surfaces as having either a constant potential or a constant surface charge. The doublelayer compression approximation developed by Gregory (1975) is one convenient model that performs well for surfaces having low- to intermediate-magnitude electrostatic potentials (typical of many geological mineral surfaces) over a wide range of surface separations, and is suitable for use over moderately wide ranges of ionic strength. The electrostatic contribution to the disjoining pressure, $F_{e}$, in a symmetric electrolyte solution between parallel charged plates is related to $f$ in the compression approximation through the following relationship (Gregory, 1975):

$F_{e}(f)=c k_{B} T\left\{2\left[1+0.25\left(Y_{e, 1}+Y_{e, 2}\right)^{2} \csc h^{2}\left(\frac{\| f}{2}\right)\right]^{0.5}-\frac{\left(Y_{e, 1}-Y_{e, 2}\right)^{2} \exp (-\not f)}{1+0.25\left(Y_{e, 1}+Y_{e, 2}\right)^{2} \csc h^{2}\left(\frac{\kappa f}{2}\right)}-2\right\}$.

In Eq. 21, $\mathrm{c}$ is the ionic concentration, $Y_{e, 1}$ and $Y_{e, 2}$ are the dimensionless electrostatic potential for the two interfaces and $Y_{e}=z e \Psi_{e} / k_{B} T, 1$ and 2 represent $\mathrm{CO}_{2}$-brine water-solid surface. The variable $\kappa^{-1}$ is the electric double layer decay length or Debye length given by:

$$
\kappa^{-1}=\sqrt{\frac{\varepsilon_{0} \varepsilon_{b} k_{B} T}{2 e^{2} z^{2} c}},
$$

where $e$ is the electron charge, $z$ is the ion value, $\varepsilon_{0}$ is the vacuum permittivity, and $\varepsilon_{b}$ is the dielectric constant of brine water. The Debye length typically ranges from $\sim 1 \mathrm{~nm}$ up to a few tens of nanometers in pore water, varying with the inverse square root of ionic strength.

\subsubsection{Contact angle estimation}


The disjoining pressure isotherm curves are computed from the DLVO theory and the three intermolecular interaction forces contributing to disjoining pressure are defined above for various temperature-pressure combinations that can be encountered at $\mathrm{CO}_{2}$ storage and sequestration sites. The parameters required to compute disjoining pressure isotherm curves at specific temperaturepressure conditions are the number of ions formed, molar concentration, and the electrostatic potential $\Psi_{e}$ at the two surfaces. The disjoining pressure isotherm curves are then used to calculate the contact angle using the Frumkin-Derjaguin equation, Eq. 14. Note that in this equation, the equilibrium film thickness $f^{*}$ is set to $0.45 \mathrm{~nm}$, and the area under the disjoining pressure curve is calculated from $f=f^{*}=0.45 \mathrm{~nm}$ to $f=400 \mathrm{~nm}$.

Comparison of model contact angles with experimental measurements. The model presented above was used to compute the contact angles between $\mathrm{CO}_{2}$ and brine water at both low and high ionic strength conditions. The simulated contact angles for the low ionic strength $\left(c=1 \times 10^{-5} \mathrm{M}\right)$ brine water and at constant temperature, $T=45^{\circ} \mathrm{C}$, are presented in Figure 9a. This plot shows that the contact angles do not change significantly with changing electrostatic potential; this means that the electrostatic forces do not contribute to disjoining pressure when the ionic concentration is low. The experimentally measured contact angles at non-ionic water (Jung and Wan, 2012) are also shown in this figure, with the simulated and measured contact angles exhibiting a reasonable agreement pressures higher than approximately $18 \mathrm{MPa}$.

The contact angles simulated as a function of the electrostatic potential for a high ionic concentration ( $c=1 \mathrm{M}$ ) brine water are presented in Figure $9 \mathrm{~b}$; the temperature, pressure, and ionic concentration, $T=60^{\circ} \mathrm{C}, P=14 \mathrm{MPa}$ and $c=1 \mathrm{~mol} / \mathrm{L}$, are the same as the ones used by Al-Menhali and Krevor (2013). The computed $\rho_{b}, \rho_{\mathrm{CO}_{2}}$ and $\sigma$ values are equal to $1018 \mathrm{~kg} / \mathrm{m}^{3}, 564 \mathrm{~kg} / \mathrm{m}^{3}$ and $31.2 \mathrm{mN} / \mathrm{m}$, respectively, which are found to be very close to the reported measured density values of 1017 and $561 \mathrm{~kg} / \mathrm{m}^{3}$, for brine and $\mathrm{CO}_{2}$ (Al-Menhali and Krevor, 2013). For the given system, the simulated contact angles are located in the range of $31^{\circ}$ to $77^{\circ}$ if the electrostatic potential values vary from $0 \mathrm{mV}$ to $100 \mathrm{mV}$ (assuming the surfaces are opposite charged). The range of the simulated contact angles is slightly wider than the core-scale effective contact angle measured at the similar system Al-Menhali and Krevor (2013), who reported that the contact angles are located in the range of $40^{\circ}$ to $60^{\circ}$ by comparing the measured capillary pressure curves with strongly water-wet $\left(\theta=0^{\circ}\right)$ mercury injection capillary pressure curves.

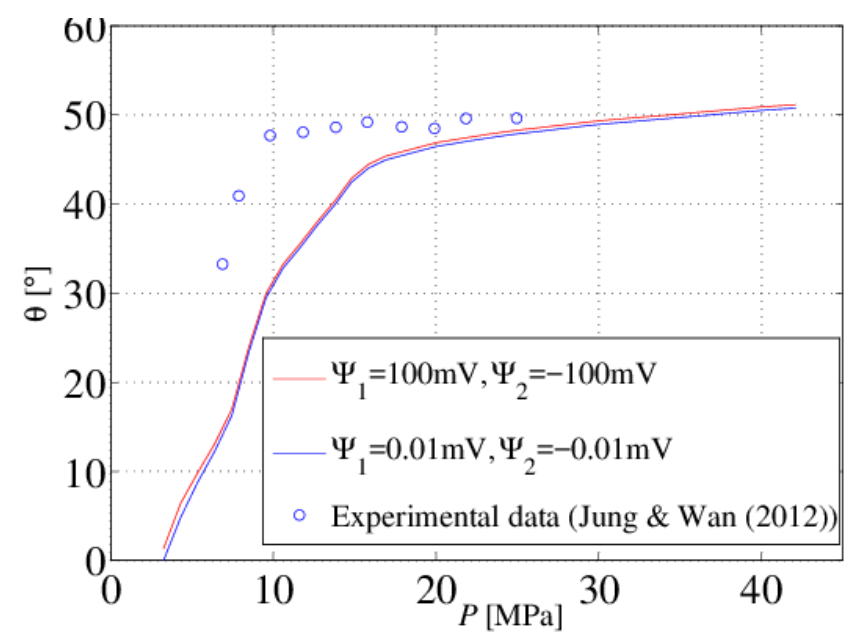

(a)

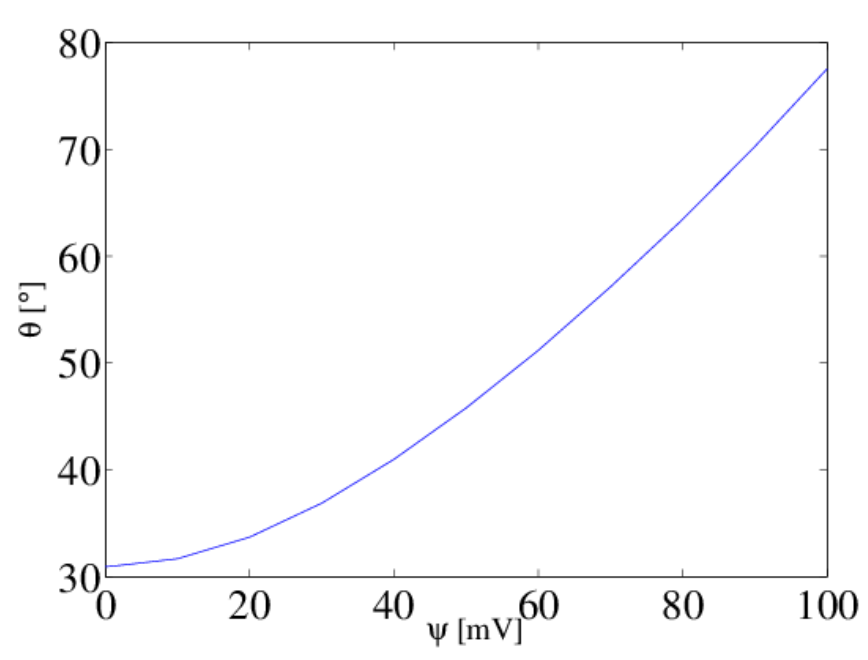

(b)

Figure 9: Contact angle in a brine- $\mathrm{CO}_{2}$-solid system for (a) a very low ionic concentration brine/water ( $c=1 \times 10^{-5} \mathrm{M}$ ) at $\mathrm{T}=45^{\circ} \mathrm{C}$, and (b) a high ionic concentration brine/water $(c=1 \mathrm{M})$ at $\mathrm{T}=60^{\circ} \mathrm{C}, \mathrm{P}=14 \mathrm{MPa}$.

Effects of electrostatic potential on contact angle. The simulated contact angles for $T=45^{\circ} \mathrm{C}$ at various ionic concentrations and electrostatic potential pairs are presented in Figure 10. This figure demonstrates that the contact angle increases with pressure at constant temperature, ionic concentration and electrostatic potential. For all cases considered, this increase occurs primarily within the pressure range of 5-20 MPa with the contact angle remaining practically constant at pressures greater than $20 \mathrm{MPa}$. The observed sharp increase of contact angle is attributed to the $\mathrm{CO}_{2}$ phase behavior as $\mathrm{CO}_{2}$ becomes supercritical at a threshold pressure (Figure 10). Note that the threshold 
pressure increases from $15 \mathrm{MPa}$ to $20 \mathrm{MPa}$ when the ionic concentration increases from $0.001 \mathrm{M}$ to $1 \mathrm{M}$. The simulated contact angle at low and high electrostatic potentials (opposite charged surfaces, $\left|\Psi_{e}\right|=0.01$ and $100 \mathrm{mV}$, respectively) exhibits an increasing difference with an enhanced brine water ionic concentration. This is because at high ionic concentration brine- $\mathrm{CO}_{2}$-solid system the attractive electrostatic forces make an important contribution to disjoining pressure, which consequently reduces the degree of water affinity on the solid surface. The simulated contact angle for $c=1 \mathrm{M}$ at larger pressure ranges varies from $48^{\circ}$ to $108^{\circ}$ (Figure 10d) as the electrostatic potential plays an increasing role in the brine- $\mathrm{CO}_{2}$-solid system. Note that for the corresponding ionic concentration $(c=1 \mathrm{M})$, the brine- $\mathrm{CO}_{2}$-solid system contact angle measured by Jung and Wan (2012) was $58^{\circ}$, which is within the range of the simulated contact angle values presented in this work.

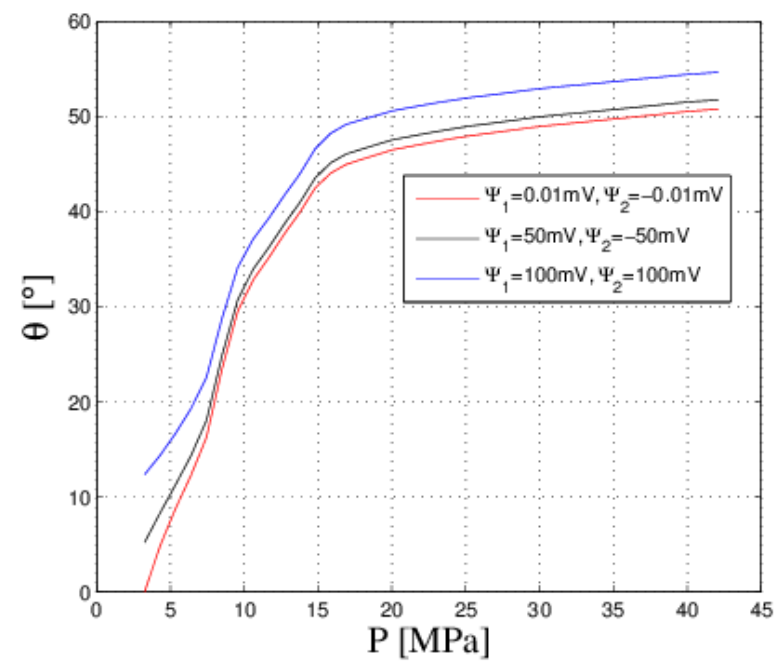

(a) $c=1 \times 10^{-3} \mathrm{M}$

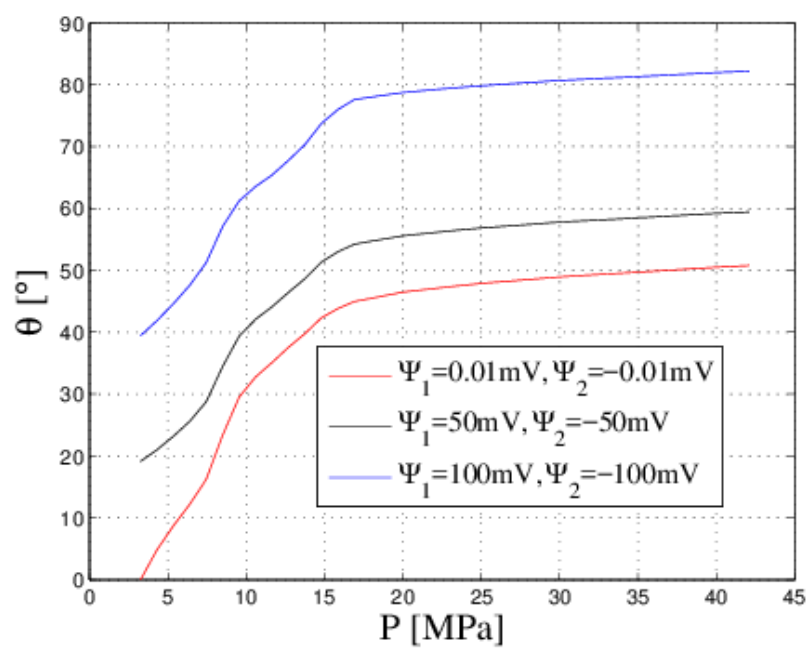

(c) $c=1 \times 10^{-1} \mathrm{M}$

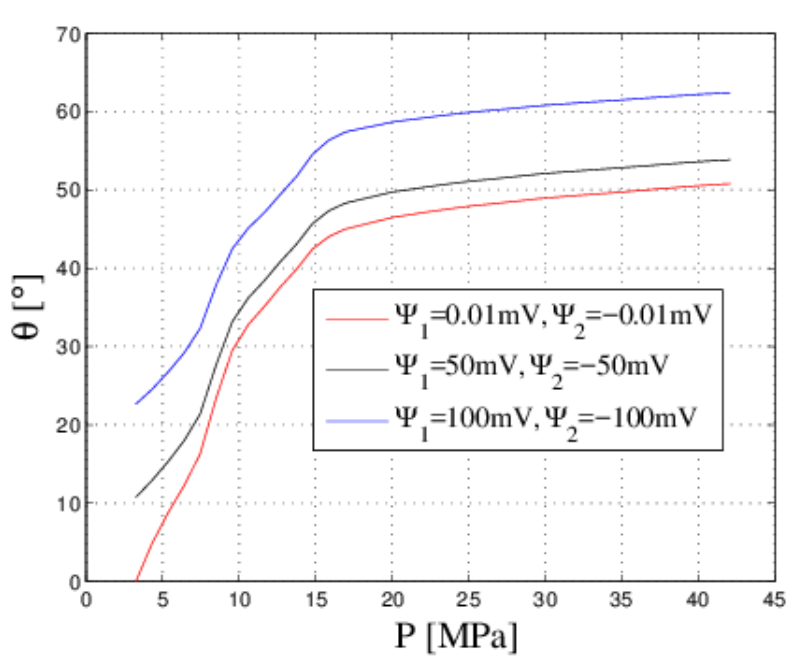

(b) $c=1 \times 10^{-2} \mathrm{M}$

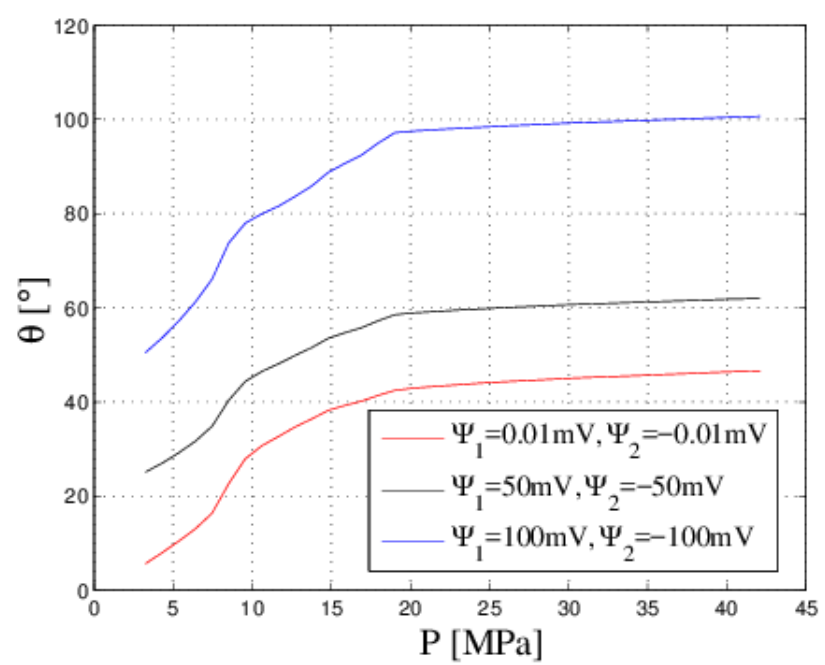

(d) $c=1 \mathrm{M}$

Figure 10: Impact of electrostatic potential on contact angle in a brine- $\mathrm{CO}_{2}$-solid system at $T=45^{\circ} \mathrm{C}$ (a)

$$
c=1 \times 10^{-3} \mathrm{M} \text {, (b) } c=1 \times 10^{-2} \mathrm{M} \text {, (c) } c=1 \times 10^{-1} \mathrm{M} \text {, and (d) } c=1 \mathrm{M} \text {. }
$$

Effect of ionic strength on interfacial tension and contact angle. The brine/supercritical- $\mathrm{CO}_{2}$ interfacial tension and contact angle are simulated for different ionic concentrations and $\Psi_{e, 1}=50 \mathrm{mV}, \Psi_{e, 2}=-50 \mathrm{mV}, T=45^{\circ} \mathrm{C}$ and $P=20 \mathrm{MPa}$; the results are shown in Figure 11 . This figure shows that the interfacial tension and contact angle both display an increasing trend with ionic concentration. A linear correlation between the interfacial tension and ionic concentration is observed in the simulated ionic concentration region (see Figure 11a); however, the contact angle exhibits a nonlinear trend as a function of ionic concentration (Figure 11b) with the contact angle ranging from $46^{\circ}$ to $63^{\circ}$ in this case). Juan and Wan (2012) claimed that a linear correlation exists between the measured 
contact angle and ionic concentration, which they explained by relating the electrostatic potential to ionic concentration. Figure $11 \mathrm{~b}$ also shows that the contact angle tends to reach a plateau when $c$ becomes larger than $0.8 \mathrm{M}$. It should be noted that a much higher contact angle could be obtained if a larger electrostatic potential value is applied. Finally, please note that the solid surface becomes even more $\mathrm{CO}_{2}$-wet $\left(\theta=108^{\circ}\right)$ for $\Psi_{e, 1}=100 \mathrm{mV}$ and $\Psi_{e, 2}=-100 \mathrm{mV}$ (see Figure $10 \mathrm{~d}$ ). Such $\mathrm{CO}_{2}$-wet systems were also reported by Yang et al. (2008) based on experimental results they obtained in their work.

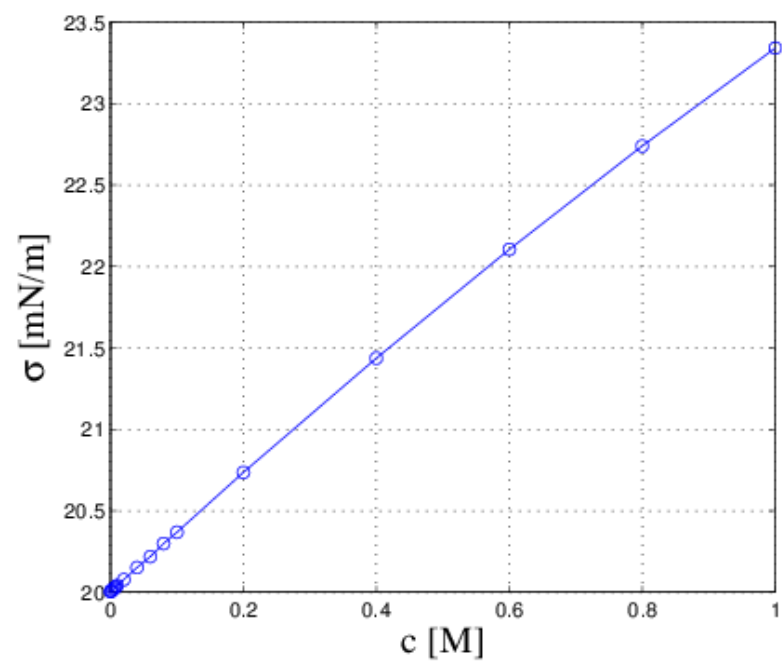

(a) Interfacial tension

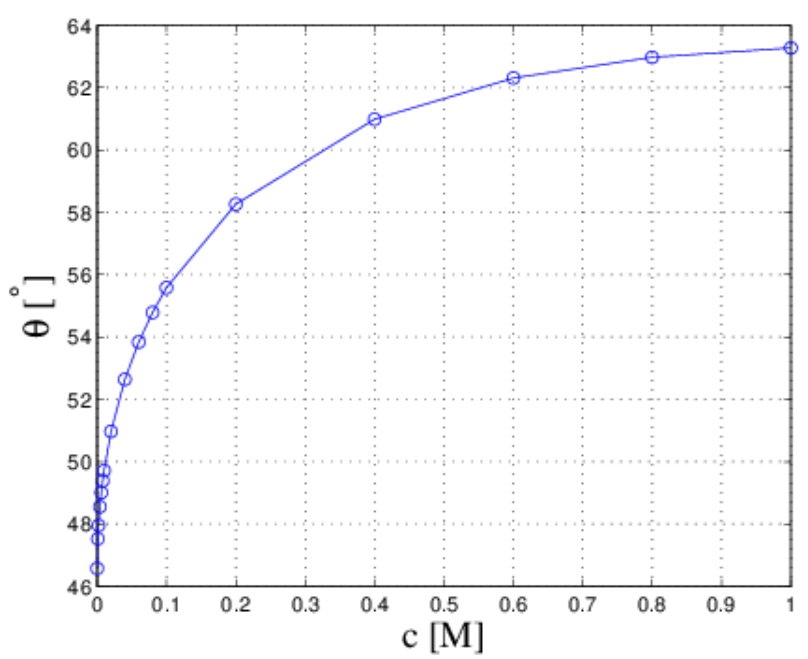

(b) Contact angle

Figure 11: Impact of ionic strength on interfacial tension and contact angle in a brine-CO2-solid system at

$$
\Psi_{e, 1}=50 \mathrm{mV}, \Psi_{e, 2}=-50 \mathrm{mV}, T=45^{\circ} \mathrm{C} \text { and } P=20 \mathrm{MPa} \text {. }
$$

Effect of temperature on contact angle. The contact angle dependency on temperature and at various pressures is investigated in this subsection. Contact angle values for temperatures $T=35^{\circ} \mathrm{C}, 45^{\circ} \mathrm{C}, 55^{\circ} \mathrm{C}, 65^{\circ} \mathrm{C}, 75^{\circ} \mathrm{C}$ ) are simulated and the results are shown in Figure 12. The electrostatic potentials used in these calculations are $\Psi_{e, 1}=50 \mathrm{mV}, \Psi_{e, 2}=-50 \mathrm{mV}$, and water brine ionic concentrations of $c=1 \times 10^{-1} \mathrm{M}$ and $c=1 \mathrm{M}$, respectively. This figure demonstrates that an increase in temperature reduces dramatically the contact angle, especially at intermediate pressures (5 MPa -15 MPa). The same effect of temperature on contact angle was also identified by Iglauer et al. (2012) based on molecular dynamic modeling.

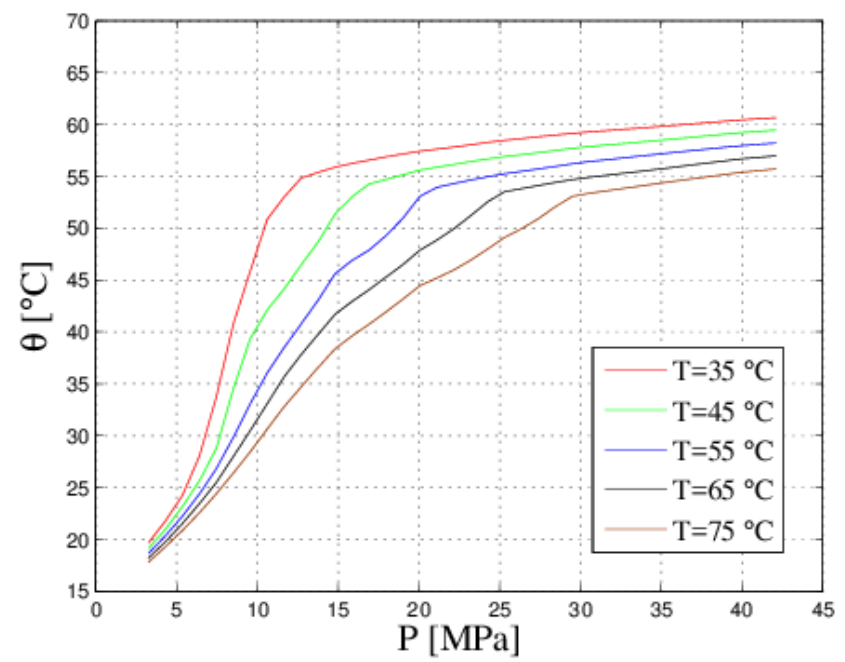

(a) $c=1 \times 10^{-1} \mathrm{M}$

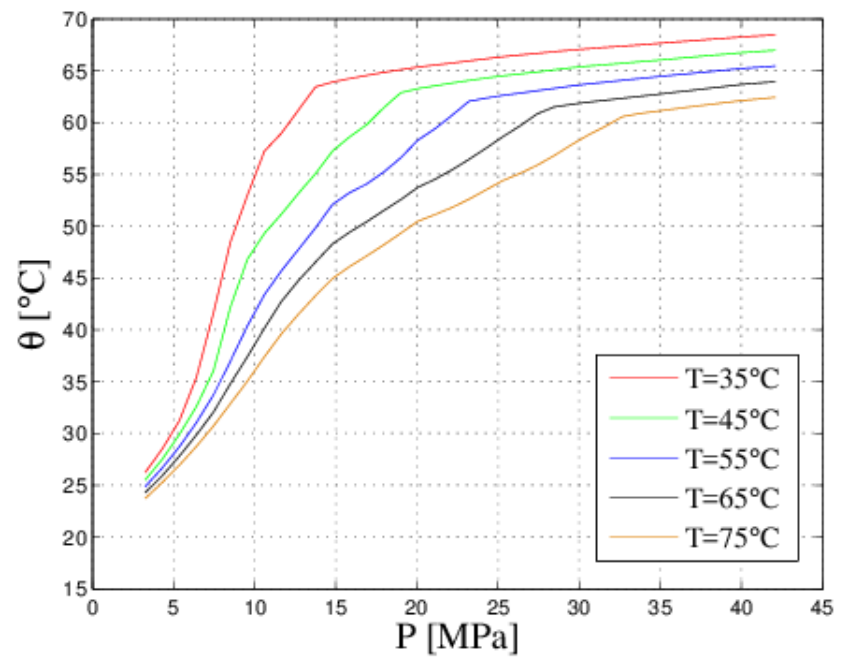

(b) $c=1 \mathrm{M}$

$440 \quad$ Figure 12: Impact of temperature on contact angle in a brine-CO2-solid system for constant charged surfaces pairs $\Psi_{e, 1}=50 \mathrm{mV}$ and $\Psi_{e, 2}=-50 \mathrm{mV}$. 


\section{Field Case}

443 The importance of the proposed methodology and presented computational approach can be viewed in 444 terms of obtaining: (a) threshold capillary pressure which is related to one of the main $\mathrm{CO}_{2}$ geological 445 storage mechanisms; and (b) entry pressure which can lead to very different predictions of long-term $446 \quad \mathrm{CO}_{2}$ sequestration ( $\mathrm{Li}$ et al., 2013).

447 The derived procedures and outlined models are used in a synthetic $\mathrm{CO}_{2}$ geological site (based on 448 Utsira formation) to obtain estimates of the capillary entry pressure as a function of $\mathrm{CO}_{2}$ storage depth. 449 The application of the entire proposed workflow (methodology) presented in this work requires detailed 450 laboratory analyses on site-specific rosk and fluid(s) samples and subsequent modeling to obtain entry 451 capillary pressures and their spatial and stress-dependent variability. Since $\mathrm{CO}_{2}$ storage sites are very 452 few globally, and since some of our methodology-required data can be found in the public domain for 453 the Utsira formation, a "synthetic" storage site based on the existing Utsira data is considered to 454 demonstrate the application of our work. In this synthetic, Utsira-like site the surface pressure is 0.105 $\mathrm{MPa}$, the pressure gradient is $10.5 \mathrm{MPa} / \mathrm{km}$, the surface temperature is $20^{\circ} \mathrm{C}$ and the temperature gradient is $20.5 \mathrm{~K} / \mathrm{km}$. The ionic components and concentration of formation brine are reported by Rochelle and Moore (2002) for a synthetic Utsira pore water. The electrostatic potentials for constant charged surface pairs are $\Psi_{e, 1}=50 \mathrm{mV}, \Psi_{e, 2}=-50 \mathrm{mV}$.

The density of $\mathrm{CO}_{2}$ and brine/water under various depths is estimated first, and subsequently the interfacial tensions and contact angles are modelled for the given $\mathrm{CO}_{2} /$ brine/solid system. Computed interfacial tensions and contact angles are presented as a function of the $\mathrm{CO}_{2}$ stored depth in Figure 13a. Both interfacial tension and contact angle exhibit significant variations for depths shallower than $1000 \mathrm{~m}$; for higher depths the variations are more gradual with the interfacial tension being close to 26 $\mathrm{mN} / \mathrm{m}$ and the contact angle around $56^{\circ}$. This is because $\mathrm{CO}_{2}$ becomes supercritical at depths in the range of $700-1000 \mathrm{~m}$ (depending on the localized pressure gradient), and the dependency of $\mathrm{CO}_{2}$ properties on pressure-temperature becomes less important.

467 The capillary entry pressure at given interfacial tension and wetting conditions when $\mathrm{CO}_{2}$ invades waterfilled, highly irregular realistic pore spaces can be estimated by the following equation which can be obtained by combining Eqs. 8 and 9:

$$
P_{c E}=\frac{\sigma}{r_{E}}=\frac{\sigma \cos \theta}{g(\theta)} \frac{L}{A}
$$

470 Please note that $g(\theta)$ is a correlation of $\cos \theta$ given by Eq. (9), and when $g(\theta)=1$ the impact of surface 471 roughness and non-convexity in the computation of the capillary entry pressure is neglected.

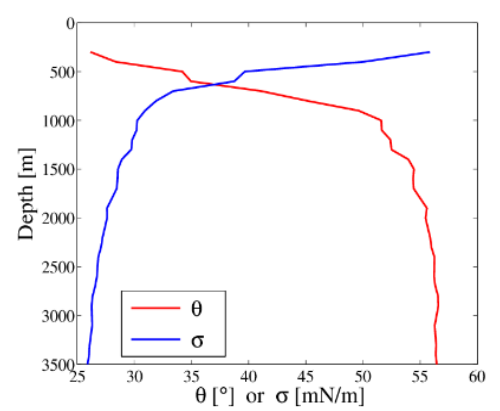

(a)

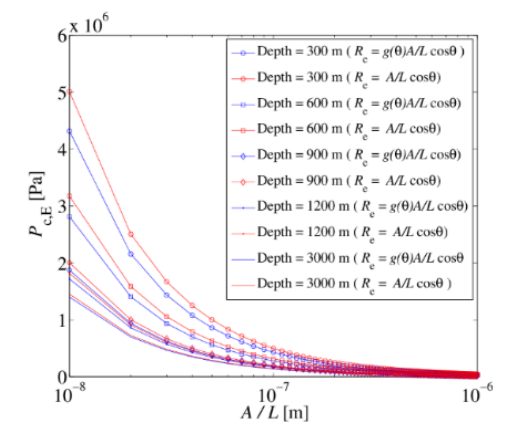

(b)

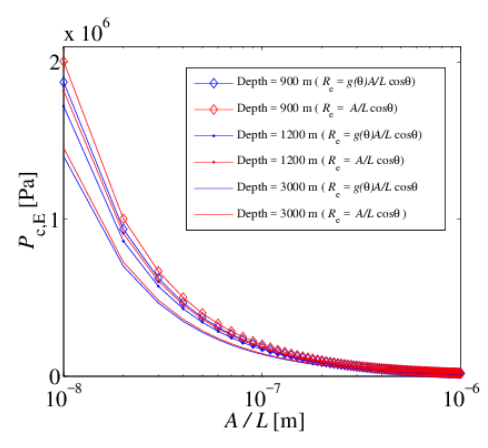

(c)
472

473 474

475

476

477

478

479

480

481

Figure 13: Dependency of (a) $\mathrm{CO}_{2} /$ synthetic-Utsira-pore-water interfacial tension and contact angle with synthetic Utsira formation depth, (b) capillary entry pressure as a function of hydraulic radius at several depths, and (c) capillary entry pressure as a function of hydraulic radius after $\mathrm{CO}_{2}$ become supercritical.

Capillary entry pressures for $\mathrm{CO}_{2}$ invading pore spaces filled with synthetic Utsira pore water for $g(\theta)=1$ (ideal case) and $g(\theta) \neq 1$ (realistic case) computed from Eq. 23 are plotted versus hydraulic radius in Figure 13b. This figure shows that $\mathrm{CO}_{2}$ capillary entry pressure depends more on depth for burial values less than $1000 \mathrm{~m}$; if the $\mathrm{CO}_{2}$ is stored deeper than $1200 \mathrm{~m}$ this variation is not as significant as depth increases. The difference between the red and blue curves is also significant if the storage depth is shallower than $900 \mathrm{~m}$, indicating that the pore space roughness and non-convexity induce lower capillary entry pressures that are needed for a safe $\mathrm{CO}_{2}$ storage. The impact of roughness and non-convexity on 
the capillary entry pressure is less important when the depth increases beyond $1200 \mathrm{~m}$; this is because $g(\theta) \rightarrow 1$ for values of $\theta$ close to $63^{\circ}$ (Figure 13b).

In order to emphasize on storage formations at depths higher than $900 \mathrm{~m}$, Figure $13 \mathrm{c}$ presents the capillary entry pressure for storage depth deeper than $900 \mathrm{~m}$ for various hydraulic radii, $A / L$. It should be noted that for a given hydraulic radius, $A / L$, the variation of capillary entry pressure is not strongly dependent on storage depth, and the pore roughness may be neglected. However, for small pore throats, the difference between the capillary entry pressure calculated at various storage depths should be considered.

In Figures 13b and 13c, the hydraulic radius $A / L$ for a circular geometry becomes $\frac{A}{L}=\frac{\pi R^{2}}{2 \pi R}=\frac{R}{2}$, so it represents the pore throat size. In Figures $13 \mathrm{~b}$ and $13 \mathrm{c}$, the hydraulic radius varies from $10^{-8} \mathrm{~m}$ to $10^{-6}$ $\mathrm{m}$; this range represents pore throat radii varying from $20 \mathrm{~nm}$ to $2000 \mathrm{~nm}$. This is a reasonable pore throat radii range for a sorage formation cap rock; for example, the pore throat diameter of the Utsira caprock is in the range of $14 \mathrm{~nm}$ to $40 \mathrm{~nm}$ (Kemp et al., 2001). The capillary entry pressure of supercritical $\mathrm{CO}_{2}$ is between $2 \mathrm{MPa}$ and $5.5 \mathrm{MPa}$, assuming the $\mathrm{CO}_{2} /$ brine surface tension to be around $20 \times 10^{-3} \mathrm{~N} / \mathrm{m}$. In order to account for the effective stress within the Sleipner area, the capillary entry pressure to supercritical $\mathrm{CO}_{2}$ in the Utsira caprock is considered to be around $1.7 \mathrm{MPa}$ (Kemp et al., 2002). This is comparable with our simulated capillary entry pressure when $\mathrm{CO}_{2}$ becomes supercritical at storage depths greater than $900 \mathrm{~m}$.

Discussion. As suggested by Chiquet et al. (2007), for $\mathrm{CO}_{2}$ storage in an aquifer, the storage capacity could be expressed in terms of mass of $\mathrm{CO}_{2}$ per unit surface of the reservoir as:

$$
M=\frac{2 \sigma \rho_{\mathrm{CO}_{2}} \phi\left(1-S_{w}\right)}{\left(\rho_{w}-\rho_{\mathrm{CO}_{2}}\right) g R},
$$

This expression of $\mathrm{CO}_{2}$ storage capacity assumes the reservoir wettability to be strongly water wet, $\theta=0$ thus overestimating the storage capacity; in addition, the density terms were assumed to remain constant. These assumptions could be addressed/improved by considering the results presented in our work for the $\mathrm{CO}_{2}$ storage in an aquifer. Following Chiquet et al. (2007) and considering that the stored $\mathrm{CO}_{2}$ occupies a given reservoir thickness, $\mathrm{h}$, between the caprock and the underlying aquifer, the buoyancy force of water that drives the $\mathrm{CO}_{2}$ upwards is given by:

$$
P_{c E}=\int_{0}^{H}\left(\rho_{w}(z)-\rho_{\mathrm{CO}_{2}}(z)\right) g d z,
$$

where $\mathrm{H}$ represents the maximum height in the formation that $\mathrm{CO}_{2}$ can be stored. The caprock's capillary entry pressure is given by Eq. 23 , so the storage capacity expressed in terms of mass of $\mathrm{CO}_{2}$ per unit surface of the reservoir is given as:

$$
M=\int_{0}^{H} \rho_{\mathrm{CO}_{2}}(z) \phi\left(1-S_{w}\right) d z=\left[\int_{0}^{H} \rho_{w}(z) d z-\frac{\sigma \cos \theta}{g(\theta)} \frac{L}{g A}\right] \phi\left(1-S_{w}\right) .
$$

This expression accounts for brine and $\mathrm{CO}_{2}$ densities, interfacial tension, and contact angle variation at different storage heights; it also accounts for the size and shape of pore space. Note that the expression of Eq. 26 is simplified to Eq. 24 if the brine and $\mathrm{CO}_{2}$ densities, interfacial tension and contact angle remain constant independent of height and the pore space geometry is circular. The depth of the top of the Utsira sand ranges from 550 to $1500 \mathrm{~m}$ and the base from 600 to $1700 \mathrm{~m}$ (Kirby, 2001); therefore, the effect of depth dependent properties on storage capacity cannot be ignored, especially when $\mathrm{CO}_{2}$ is close to the critical point (Chadwick et al., 2008).

Summarizing, the proposed methodology is capable of providing estimates of the depth-dependent capillary entry pressure in the context of geological $\mathrm{CO}_{2}$ storage based on the storage-specific characteristics (rock and fluids) and conditions (pressure, temperature and brine ionic composition). These figures can reduce site-specific uncertainties and provide relevant scientific support for a more realistic and safely-executed $\mathrm{CO}_{2}$ storage project. A future application of simulated depth-dependent capillary entry pressure curves can also be incorporated into existing reservoir simulation models to 
predict $\mathrm{CO}_{2}$ migration in the storage unit and overburden strata in case of a potential, and unwanted, $\mathrm{CO}_{2}$ leakage.

\section{Summary and Conclusions}

A method is proposed for estimating the capillary entry radii for $\mathrm{CO}_{2}$ invading brine-water filled irregular pore space geometries under arbitrary uniformly-wet conditions. The brine $/ \mathrm{CO}_{2}$ contact angle as a function of pressure-temperature, ionic strength, and electrostatic potential is computed from the Frumkin-Derjaguin equation and based on the DLVO theory. A case study is used to illustrate the dependency of $\mathrm{CO}_{2}$ capillary entry pressure with formation depth. Based on the theory and results presented in this work, the following conclusions can be made:

- The simulated brine/CO $\mathrm{CO}_{2}$ contact angles exhibit a qualitative agreement with experimental measurements reported in literature. Specifically, the following observations are very important, and contact angle behavior needs to be accounted for in modeling of $\mathrm{CO}_{2}$ geological storage processes:

- Contact angle increases with electrostatic potential; this increase occurs primarily within the pressure range of 5-15 $\mathrm{MPa}$, which corresponds to a $\mathrm{CO}_{2}$ storage depth of 500 $1500 \mathrm{~m}$, if a normal hydrostatic pressure gradient is applied.

- Contact angle exhibits a non-linear trend as a function of brine ionic concentration.

- Contact angle is reduced dramatically with increasing temperature, especially at intermediate pressures.

- Pore roughness and shape are important when predicting $\mathrm{CO}_{2}$ capillary entry pressure as a function of hydraulic radius for storage depths shallower than $1000 \mathrm{~m}$, i.e., when $\mathrm{CO}_{2}$ is not supercritical; these effects become less impotant when $\mathrm{CO}_{2}$ storage occurs at depths over than $1200 \mathrm{~m}$.

- For the given pore size and shape, the capillary entry pressure for $\mathrm{CO}_{2}$ invading pore spaces filled with synthetic Utsira pore water is highly dependent on the storage depth when shallower than $1000 \mathrm{~m}$; for storage depth deeper than $1200 \mathrm{~m}$ the variation in $\mathrm{CO}_{2}$ capillary entry pressure reduces as formation depth increases.

\section{Acknowledgements}

552 This work was partially funded by the Research Council of Norway through a CLIMIT project, ConocoPhillips and the Ekofisk co-venturers, including TOTAL, ENI, Statoil and Petoro. We thank the anonymous reviewers whose comments/suggestions helped to improve the written presentation of this manuscript.

\section{Nomenclature}

$557 \mathrm{~A}=$ Area, $\mathrm{m}^{2}$

$558 \mathrm{C} \quad=\quad$ Ionic concentration, $\mathrm{mol} / \mathrm{L}$

$559 \mathrm{E}=$ Bulk modulus of elasticity, $\mathrm{MPa}$

$560 \mathrm{~F}=$ Force, $\mathrm{N}$

$561 \mathrm{H}=$ Hamaker constant, $\mathrm{J}$

$562 \mathrm{~h}=$ Thickness, $\mathrm{m}$

$563 \mathrm{kB}=$ Boltzmann constant, $1.38064852 \times 10^{-23} \mathrm{~J} / \mathrm{K}$

$564 \mathrm{~L} \quad=\quad$ Length, $\mathrm{m}$

$565 \mathrm{M}=\quad$ Mass of $\mathrm{CO}_{2}$ per reservoir unit surface, $\mathrm{kg} / \mathrm{m}^{2}$

$566 \mathrm{n}=$ Refractive index, dimensionless

$567 \mathrm{P} \quad=\quad$ Pressure, $\mathrm{Pa}$

$568 \mathrm{r} \quad=\quad$ Radius, $\mathrm{m}$

$569 \mathrm{R}=$ Largest pore throat size in caprock, $\mathrm{m}$ 


\begin{tabular}{|c|c|c|c|}
\hline 570 & S & $=$ & Saturation, fraction \\
\hline 571 & $\mathrm{~T}$ & $=$ & Temperature, ${ }^{\circ} \mathrm{C}$ \\
\hline 572 & $\mathrm{Y}$ & $=$ & Electrostatic potential, dimensionless \\
\hline 573 & \multicolumn{3}{|c|}{ Greek Letters } \\
\hline 574 & $\beta$ & $=$ & Volumetric temperature expansion coefficient, $1 /{ }^{\circ} \mathrm{C}$ \\
\hline 575 & $\varepsilon$ & $=$ & Dielectric constant, dimensionless \\
\hline 576 & $\varepsilon_{0}$ & $=$ & Vacuum permittivity, $8.854187817 \times 10^{-12} \mathrm{~F} / \mathrm{m}$ \\
\hline 577 & $\theta$ & $=$ & Contact angle, degrees \\
\hline 578 & K & $=$ & Inverse of Debye length, $1 / \mathrm{m}$ \\
\hline 579 & $\Pi$ & $=$ & Disjoining pressure, $\mathrm{Pa}$ \\
\hline 580 & $\rho$ & $=$ & Density, $\mathrm{kg} / \mathrm{m}^{3}$ \\
\hline 581 & $\sigma$ & $=$ & Interfacial tension, $\mathrm{mN} / \mathrm{m}$ \\
\hline 582 & $\phi$ & $=$ & Porosity, fraction \\
\hline 583 & $\Psi$ & $=$ & Electrostatic potential, $\mathrm{mV}$ \\
\hline 584 & \multicolumn{3}{|c|}{ Subscripts } \\
\hline 585 & $b$ & $=$ & Brine \\
\hline 586 & c & $=$ & Capillary \\
\hline 587 & $E$ & $=$ & Entry \\
\hline 588 & e & $=$ & Electrostatic \\
\hline 589 & $\mathrm{~s}$ & $=$ & Structural or solid \\
\hline 590 & vDW & $=$ & van der Waals \\
\hline 591 & w & $=$ & Water \\
\hline
\end{tabular}

\section{References}

Al-Menhali, A. and Krevor, S., (2013), Pressure, temperature and ionic strength effects on the wettability of $\mathrm{CO}_{2}$-brine-sandstone system: core-scale contact angle measurements. Paper SCA 2013-03, Napa Valley, California, USA, 16-19 September.

Ameri, A., Kaveh, N. S., Rudolph, E.S.J., Wolf, K. H., Farajzadeh, R., and Bruining, J., (2013), Investigation on interfacial interactions among crude oil-brine-sandstone rock- $\mathrm{CO}_{2}$ by contact angle measurements, Energy Fuels, 27 (2), 1015-1025. doi:10.1021/ef3017915.

Bachu, S., and Bennion, B., (2009), Interfacial tension between $\mathrm{CO}_{2}$, freshwater, and brine in the range of pressure (2 to 27 ) $\mathrm{MPa}$, temperature (20 to 125$)^{\circ} \mathrm{C}$, and water salinity from (0 to 334000 ) mg. $\mathrm{I}^{-1}$, J. Chem. Eng. Data, 54 (3), 765-775. doi:10.1021/je800529x.

Bradley, D. J. and Pitzer, K. S., (1979), Thermodynamics of electrolytes. 12. Dielectric properties of water and Debye-Hückel parameters to $350^{\circ} \mathrm{C}$ and 1 kbar, J. Phys. Chem., 83 (12), 15991603. doi:10.1021/j100475a009.

Braquelaire, J. P. and Vialard, A., (1999), Euclidean paths: a new representation of boundary of discrete regions, Graph Models Image Process, 61, 6-43.

Celia, M. A., (2008), Geological storage as a carbon mitigation option; Henry Darcy Distinguished Lecture Series in Ground Water Science.

Chalbaud, C., Robin, M., Lombard, J. M., Martin, F., Egermann, P., and Bertin, H., (2009), Interfacial tension measurements and wettability evaluation for geological $\mathrm{CO} 2$ storage, Adv. Water Resour., 32(1), 98-109. doi:10.1016/j.advwatres.2008.10.012.

Chadwick, A., Arts, R., Bernstone, C., May, F., Thibeau, S. and Zweigel, P., (2008), Best practice for the storage of $\mathrm{CO}_{2}$ in saline aquifers: Observations and guidelines from the SACS and CO2STORE projects.

Chiquet, P., Broseta, D., and Thibeau, S., (2005), Capillary alteration of shaly caprocks by carbon dioxide. Paper SPE 94183 presented at the Europec/EAGE Annual Conference, Madrid, Spain, 13-16 June. 
Chiquet, P., Daridon, J.L., Broseta, D., Thibeau, S., (2007), $\mathrm{CO}_{2} /$ water interfacial tensions under pressure and temperature conditions of $\mathrm{CO}_{2}$ geological storage. Energy Conversion and Management 48 (3), $736 \mathrm{e} 744$.

Chaturvedi, T., Schembre, J. M., and Kovscek, A. R., (2009), Spontaneous imbibition and wettability characteristics of Powder River Basin coal. International Journal of Coal Geology, 77, 34-42.

Deming, D., 2001. Introduction to Hydrogeology. McGraw-Hill: New York.

Farokhpoor, R., Bjørkvik, B. J. A., Lindeberg, E., and Torsæter, O., (2013), Wettability behavior of $\mathrm{CO}_{2}$ at storage conditions, International Journal of Greenhouse Gas Control, (12), 18-25. doi:10.1016/j.ijggc.2012.11.003.

Frette, O. I. and Helland, J. O., (2010), A semi-analytical model for computation of capillary entry pressures and fluid configurations in uniformly-wet pore spaces from 2D rock images. $A d v$. Water Resour. 33 (8), 846-866. doi:10.1016/j.advwatres.2010.05.002.

Gregory, J., (1975), Interaction of unequal double layers at constant charge, Journal of Colloid and Interface Science, (51) 1, 44-51. doi:10.1016/0021-9797(75)90081-8.

Harvey, A. H., Gallagher, J. S. and Levelt Sengers, M. H., (1998), Revised formulation for the refractive index of water and steam as a function of wavelength, temperature and density, J. Phys. Chem. Ref. Data, 27, 761. doi:10.1063/1.556029.

Hebach A., Oberhof A., Dahmen N., Kögel A., Ederer H., and Dinjus E., (2002), Interfacial tension at elevated pressures-measurements and correlations in the water + carbon dioxide system. $J$. Chem. Eng. Data, 47 (6), 1540-1546. doi:10.1021/je025569p.

Helland, J. O. and Frette O. I., (2010), Computation of fluid configurations and capillary pressures in mixed-wet 2D pore spaces from rock images. Proceedings of the XVIII International Conference on Water Resources, Barcelona, Spain.

Hirasaki, G. J., (1991), Thermodynamics of thin films and three-phase contact regions, Interfacial Phenomena in Oil Recovery, Morrow, N. R. (Ed.), Marcel Dekker Inc., New York, 23-76, 2000.

Israelachvili, J., (1991), Intermolecular \& Surface Forces. Academic Press, 2nd Edition.

Iglauer, S., Mathew, M., and Bresme, F., (2012), Molecular dynamics computations of brine- $\mathrm{CO}_{2}$ interfacial tensions and brine- $\mathrm{CO}_{2}$-quartz contact angles and their effects on structural and residual trapping mechanisms in carbon geo-sequestration. J. Coll. Inter. Sci., 386 (1), 405-414. doi:10.1016/j.jcis.2012.06.052.

Jung, J. and Wan, J., (2012), Supercritical $\mathrm{CO}_{2}$ and ionic strength effects on wettability of silica surfaces: Equilibrium contact angle measurements, Energy \& Fuels, 26 (9), 6053-6059. doi:10.1021/ ef300913t

Kaveh, N. S., Rudolph, E. S. J., Rossen, W. R., van Hemert, P., and Wolf, K. H., (2012), Interfacial tension and contact angle determination in water-sandstone systems with injection of flue gas and $\mathrm{CO}_{2}$, 17th European Symposium on Improved Oil Recovery, 16 - 18 April 2013, Saint Petersburg, Russia.

Kemp, S. J., Bouch, J. and Murphy, H. M., (2001), Mineralogical characterisation of the Nordland Shale, UK Quadrant 16, Northern North Sea. British Geological Survey Commissioned Report, $\mathrm{CR} / 01 / 136$.

Kemp, S. J., Pearce, J. M, and Steadman, E. J., (2002) Mineralogical, geochemical and petrographical characterisation of Nordland Shale cores from well 15/9-A-11, Sleipner field, northern North Sea. British Geological Survey Commissioned Report, CR/02/313.

Kim, Y., Wan, J., Kneafsey, T. J., and Tokunaga, T. K., (2012), Dewetting of silica surfaces upon reactions with supercritical $\mathrm{CO}_{2}$ and brine: Pore-scale studies in micromodels, Environ. Sci. Technol., 46 (7), 4228-4235. doi:10.1021/es204096w.

Kirby, G. A., (2001) Depth mapping and characterisation of the Utsira Sand saline aquifer, Central and Northern North Sea. British Geological Survey Report CR/01/218N.

Lago, M. and Araujo, M., (2001), Threshold pressure in capillaries with polygonal cross section. J. Colloid Interf. Sci. 243 (1), 219-226. doi:10.1006/jcis.2001.7872.

Li, B., Tchelepi, H. A. and Benson, S. M., (2013), Influence of capillary-pressure models on $\mathrm{CO}_{2}$ solubility trapping, Advances in Water Resources, 62, Part C, 488-498. doi:10.1016/j.advwatres.2013. 08.005.

Lindquist, W. B., (2006), The geometry of primary drainage. J. Coll. Interf. Sci. 296 (2), 655-668. doi:10.1016/j.jcis.2005.09.041.

Ma, S., Mason, G., and Morrow, N. R., (1996), Effect of contact angle on drainage and imbibition in regular polygonal tubes. Colloids Surf., A Physicochem. Eng. Asp. 117, 273-291.

Michels, A. and Michels, C., (1933), The influence of pressure on the dielectric constant of carbon dioxide up to 1000 atmospheres between $25^{\circ}$ and $150{ }^{\circ} \mathrm{C}$. Philosophical Transactions of the Royal Society of London A: Mathematical, Physical and Engineering Sciences, 231, 694-706. doi:10.1098/rsta.1933.0011. 
Øren, P. E., Bakke, S., and Arntzen, O. J., (1998), Extending predictive capabilities to network models. SPE Journal 3(4), 324-336. December. SPE-52052-PA. doi:10.2118/52052-PA.

Plug, W. J. and Bruining, J., (2008), Capillary pressure for the sand- $\mathrm{CO}_{2}-$ water system under various pressure conditions. Application to $\mathrm{CO}_{2}$ sequestration. Adv. Water Resour. 30 (11), 2339-2353. doi:10.1016/j.advwatres.2007.05.010.

Rochell, C. A. and Moore, Y. A., (2002), The solubility of supercritical $\mathrm{CO}_{2}$ into pure water and synthetic Utsira pore water. British Geological Survey, Commissioned report CR/02/052.

Tokunaga, T. K., (2012), DLVO-based estimates of adsorbed water film thicknesses in geologic $\mathrm{CO}_{2}$ reservoirs. Langmuir, 28 (21), 8001-8009. doi:10.1021/la2044587.

Tokunaga, T. K., Wan, J., Jung, J. W., Kim, T. W., Kim, Y., and Dong, W., (2013), Capillary pressure and saturation relations for supercritical $C_{2}$ and brine in sand: High-pressure $P_{c}\left(S_{w}\right)$ controller/meter measurements and capillary scaling predictions. Water Resources Research, 49, 4566-4579. doi:10.1002/wrcr20316.

Thomas, L. K., Katz, D. L., and Tek, M. R., (1968), Threshold pressure phenomena in porous media. Society of Petroleum Engineers, 8(02), 174-184. doi:10.2118/1816-PA.

Span, R. and Wagner, W., (1996), A new equation of state for carbon dioxide covering the fluid region from the triple-point temperature to $1100 \mathrm{~K}$ at pressures up to $800 \mathrm{MPa}$. J. Phys. Chem. Ref. Data, 25, 1509- 1596. doi:10.1063/1.555991.

Sun, Y., Shekunova, B. Y., and York, P., (2003), Refractive index of supercritical $\mathrm{CO}_{2}$-ethanol solvents, Chemical Engineering Communications, 190 (1), 1-14. doi:10.1080/00986440302089.

Wang, S. and Tokunaga, T. K., (2015), Capillary pressure-saturation relations for supercritical $\mathrm{CO}_{2}$ and brine in limestone/dolomite sands: Implications for geologic carbon sequestration in carbonate reservoirs, Environ. Sci. Technol., 49, 7208-7217. doi:10.1021/acs.est.5b00826.

Yang, D., Gu, Y., and Tontiwachwuthikul, P., (2008), Wettability determination of the reservoir brinereservoir rock system with dissolution of $\mathrm{CO}_{2}$ at high pressures and elevated temperatures, Energy \& Fuels, 22 (1), 504-509. doi:10.1021/ef700383x.

Zhou, Y., Helland, J. O., and Hatzignatiou, D. G., (2013), A dimensionless capillary pressure function for imbibition derived from pore-scale modeling in mixed-wet-rock Images. SPE Journal. 18 (2): 296-308. SPE-154129-PA. doi:10.2118/154129-PA.

Zhou, Y., Helland, J. O., and Hatzignatiou, D. G., (2014), Computation of three-phase capillary entry pressures and arc menisci configurations in pore geometries from $2 \mathrm{D}$ rock images: $\mathrm{A}$ combinatorial approach, Advances in Water Resources, Vol. 69, July, 49-64. doi:10.1016/j.advwatres.2014.03.006. 